\title{
La propiedad en la Isla Taquile, Lago Titicaca
}

\author{
José Matos Mar \\ jmatos@speedy.com.pe \\ Profesor Emérito. UNMSM
}

\begin{abstract}
Resumen
Un ensayo etnológico y etnohistórico que describe la lucha por la propiedad de las tierras de cultivo de una comunidad indígena de habla quechua ubicada en una isla del Lago Titicaca. En la segunda mitad del siglo XVI fue adjudicada en remate a un español y desde entonces en sucesivos remates a otros hasta el siglo XVIII en que propietarios puneños la explotaron como su hacienda considerando colonos a sus habitantes.En 1942 los indigenas lograron iniciar la compra de sus tierras con título de propiedad, una singular reforma agraria que los hizo dueños respaldados por documentos públicos. Estudio apasionante de las vicisitudes y luchas por lograrlo y de la situación de la isla Taquile en la década 1950.

Palabras clave: Antropología, etnografía, etnología, etnohistoria, reforma agraria, propiedad, comunidad campesina de hacienda, emergencia de comunidades de éxito.
\end{abstract}

\begin{abstract}
An ethnological and ethno-historical essay that describes the struggle for the ownership of farmland in a Quechua speaking native community located in an island on Lake Titicaca.

Taquile was sold at auction to a Spaniard during the second half of the XVI century and then successively to others at several auctions until the XVIII century, when owners from Puno developed it as their own estate, referring to its inhabitants as settlers. A remarkable agrarian reform began in 1942, when the natives started buying their land and obtaining official title deeds to their property. A passionate study about their struggle to achieve this and the state of affairs in Taquile island during the fifties.
\end{abstract}

Keywords: Anthropology, ethnography, ethnology, ethno-history, land reform, property, peasant community, the emergence of successful communities. 


\section{Características generales de la cultura en Taquile}

Taquile constituye un grupo homogéneo de 640 habitantes (Censo del autor 1952), distribuido en 113 familias que ocupan una de las seis islas pobladas del lago Titicaca ubicado a 3830 metros de altitud. En ese entonces sólo hablaban castellano dos adultos y seis niños, el resto tenía como idioma el quechua.

Es un típica comunidad indígena agrícola que desde el siglo XVI, 1580, formó parte del sistema de hacienda en su variante de la meseta del Collao hasta 1942 en que comenzaron los indígenas a comprar las tierras en poder de hacendados puneños. Dentro del conjunto de las comunidades indígenas peruanas, al que pertenece de hecho, ocupa el nivel más tradicional, de manera que es un grupo que mantiene desde hace siglos una economía de consumo. Por ello Taquile es representativo de lo que podría considerarse "puramente" indígena en esta década de 1950, es decir una supervivencia o relicto más representativo de lo que fue el mundo prehispánico.

Los taquileños obtienen sólo una cosecha anual pues carecen de agua para el regadío. La lluvia es así un factor determinante en su ciclo económico. La papa que es su cultivo más importante constituye la base de su alimentación y de su ingreso monetario. Otros productos que siembran son el maíz, la quinua, la cebada, los ollucos y las habas.

En la isla no hay perros, gatos, ni llamas y los pocos vacunos y ovinos son de ínfima calidad. Crían cuyes y cerdos y aves de corral, como gallinas.

La vivienda es dispersa, existiendo solamente cuatro o cinco concentraciones de dos o tres casas en algunos lugares, como consecuencia de la supervivencia de su sistema tradicional de organización social patrilineal. Los hijos al casarse ocupan una casa al lado de la del padre y crean un sistema de familia extensa que es su patrón cultural, el cual actualmente está en proceso de cambio debido a la transformación del régimen de propiedad.

El núcleo central de su vivienda es un patio rectangular a cuyo alrededor disponen de tres a cuatro habitaciones independientes que les sirven como dormitorio, depósito y cocina. A diferencia de las vecinas islas Amantani y del Sol, no existe una habitación aislada y especial para la cocina. El patio juega un papel fundamental en su vida cotidiana y comunitaria, su tamaño y las patawas o asientos de piedra que lo rodean son símbolo de estatus de prestigio. En uno de sus ángulos un pasaje de entrada comunica la vivienda con el exterior y rodeándola están las plantas de kolle, arbusto autóctono que tiene múltiples utilizaciones. Esta sería la primera circunferencia o anillo que la rodea, la segunda lo constituye el llamado canchón, o pequeño campo de cultivo donde siembran los productos que requieren más cuidado para su alimentación: habas, quinua y maíz. Allí están ubicados, también, los chiqueros para los cerdos y los corrales para los ovinos y vacunos.

Además, cada vivienda tiene un "churo" o lugar sagrado, ubicado en su pasaje de entrada y salida, donde se depositan las ofrendas que sus moradores ofrecen al espíritu del hogar (huihuac) que habita en el centro del patio. Patio, habitaciones, cerco de kolle, churo, huihuac y canchón son los elementos esenciales de una vivienda taquileña. Las paredes de pircas de piedra, los techos de ichu sobre una estructura de palos de kolle, el piso de tierra apisonada y las puertas revestidas de bosta con una cerradura especial y muy singular de madera llamada maskara, son los elementos comunes en las construcciones. Todo el sistema de vivienda responde exclusivamente a modelos tradicionales o sea a formas heredadas de la antigua cultura indígena peruana.

Existen 113 viviendas y 60 chozas desparramadas en toda la isla donde viven sus 640 habitantes y como resultado de sus trabajos comunales cuentan con servicios públicos tales como la iglesia con su torre separada, el atrio con su arco de entrada que es también la 
plaza principal de la isla y la casa del cura; todo lo que conforma el conjunto primordial de la isla, con la escuela y su patio a pocos metros de este conjunto y sus campos de cultivo circunvecinos. Todos ellos ubicados en el suyu Chuñopampa, el más importante de los seis existentes en la isla.

Además, existe una capillita en el sur de la isla; dos muelles o embarcaderos; el canchón de Mulusina, lugar mágico-religioso en la cumbre más alta de la isla, que está cercado con piedras labradas procedentes de las antiguas construcciones anteriores al siglo XVI y en el cual realizan anualmente la gran ceremonia de agradecimiento y pago a la tierra en medio de danzas y vestidos especiales que portan las tropas de sikuris. Una serie de "apachetas" o altares de piedra en lugares sagrados de la isla, destinados al culto y una red de senderos que la cruzan en todas direcciones completan esta descripción de servicios públicos. En su vida cotidiana matiza este panorama el encuentro incesante de sus pobladores en todo el ámbito de la isla saludándose y ofreciéndose coca, un puñado pequeño que extraen de sus bellas chuspas.

La transformación en el régimen de la propiedad de la tierra, que desarrollaremos ampliamente en este artículo constituye, por ahora, el centro de todas sus motivaciones y es factor decisivo en los cambios que actualmente se están operando y en el futuro de la comunidad.

En 1944 el Lago Titicaca sufrió una considerable baja en el nivel de sus aguas, descenso que responde a un ciclo constante, aunque ese año se presentó en forma más aguda. Una de las anteriores bajas ocurrió en 1925. La pérdida del nivel de agua ocasionó la ausencia total de la totora, enea que crece en las orillas y zonas de poca profundidad. Esta desaparición fue desastrosa en sus primeros momentos ya que significó la falta de materia prima para la fabricación de sus embarcaciones, las balsas de totora, como las de los uru en sus islas flotantes cercanas al puerto de Puno.

El problema creado, compartido por las otras islas y los centros poblados de las penínsulas de Chucuito y Capachica que cruzan el lago para llegar a Puno, determinó la aparición y auge posterior de los botes de vela. Esto constituyó otro factor preponderante en el cambio que actualmente se opera en todo el lago Titicaca y para Taquile un factor complementario al cambio de la propiedad. Los taquileños pudieron desde esa fecha acortar el viaje a Puno de quince a cinco horas de navegación y sin mayores penurias. El primer bote fue comprado en Puno por los hermanos Prudencio y Lino Huata el 15 de mayo de 1946 en mil soles y los otros cuatro que actualmente poseen han sido fabricados en la misma isla por los indígenas imitando a los existentes en el lago.

Propiedad y transporte han cambiado la fisonomía de la isla en estos últimos años. El grupo fuertemente solidario ha salido triunfante en una etapa crucial y estas dos categorías ahora constituyen sus "focos" culturales" (Herskovits, 1952, p. 586), o sea las instituciones de mayor complejidad y variación aunque con el carácter de integradoras y transitorias (Ruth Benedict 1944), lo que significa que en torno a estos dos factores, sobre todo el primero, se está remodelando la cultura mestiza de Taquile. Las motivaciones directoras la constituyen estos dos aspectos de la cultura del grupo, pero por su proceso creemos que tales factores integradores, que por múltiples circunstancias han tomado esta dirección, serán solamente momentáneos. Y así con respecto al transporte, casi puede afirmarse que su papel está finalizando mientras que la lucha por la propiedad todavía seguirá actuando y como veremos más adelante, cuando hagamos su análisis, constataremos que sigue un sendero favorable, cumplido el cual Taquile seguirá vinculado a su área cultural, la del Lago Titicaca, pero bajo un nuevo estatus; ya no ser un grupo de colonos aislados en una isla lejana, sino una comunidad andina serrana de campesinos mestizos. 
Estamos, pues, en presencia de un fenómeno de movilidad social de un grupo que sale del más bajo nivel dentro de todo el vasto conjunto que constituyen los grupos indígenas andinos, para pasar a ocupar un estatus más elevado dentro del mismo nivel social y cultural.

No obstante todo este conjunto de hechos fundamentales dentro de la vida de los isleños, el papel de la isla Taquile con respecto al país y su incorporación al mismo no ha sufrido cambio alguno, ni tampoco lo veremos probablemente en los próximos años. Pero sí, recalcamos, que se están acomodando a un nivel que los llevará indudablemente a mayores logros. Son propietarios de sus tierras de cultivo; el servicio personal a los dueños "mistes" casi ha desaparecido; predomina el sistema individual en el cultivo y aprovechamiento de los recursos naturales, en la economía familiar y en la selección de sus actividades. El sistema comunitario persiste en el aprovechamiento de las tierras que descansan cada año en bien de la agricultura y el pastoreo, en el cumplimiento riguroso del sistema tradicional de rotación de sus cultivos, en el respeto a sus autoridades tradicionales que son elegidas libremente por todos ellos para el buen gobierno; en los trabajos cooperativos que realizan para dotarse de servicios básicos y en sus fiestas y cargos religiosos donde la ayuda mutua funciona normalmente. Claramente se percibe una base tradicional, un espíritu colectivista, que es el denominador común de todas sus actividades lo que se manifiesta aún en sus sistemas organizativos o en sus actos individualistas. Reciprocidad y redistribución de bienes y servicios son parte sustantiva de su vida cotidiana.

La agricultura sigue tradicionales métodos y utiliza instrumentos y herramientas del antiguo mundo andino de poca eficacia; predomina el mismo complejo de plantas cultivadas que existía en tiempos del Estado Inca (papa, quinua, maíz, olluco). El sistema de trabajo mantiene las pautas de tres de sus formas tradicionales: el ayni (ayuda mutua), la minka (trabajo colectivo para obras públicas) y el yanaparicuy (ayuda mutua entre no familiares). Junto a tales formas existen el trabajo individual y las asociaciones libres de trabajo para determinadas actividades.

Toda su vestimenta es elaborada por ellos mismos a partir del hilado y tejido. El excedente de su producción agrícola les permite un pequeño comercio basado en el trueque y también en la venta por dinero. Procuran reunir, centavo a centavo, las sumas que necesitan para comprar tierras, fabricar sus embarcaciones y adquirir lo indispensable para el complemento de su consumo: fósforos, kerosene, lana, alcohol y para sus fiestas coca y ciertos adornos y objetos usados en oportunidades especiales para el pago a la pachamama. Ellos proveen al mercado exterior de papas, leña y tallados de piedra en pequeña cantidad.

La escuela no significa hasta ahora ninguna ventaja a pesar de que ingresa a su duodécimo año de funcionamiento y ello debido fundamentalmente a la falta de orientación, pues en modo alguno responde a las exigencias del medio. Ni planes, ni maestros han respondido a las necesidades de los isleños.

La lucha por la propiedad y el cambio en las comunicaciones y transporte como se ha mencionado son los factores más importantes que actúan como estímulos y que los ponen en contacto con el mundo moderno y sus logros tecnológicos. Ahora, están en constante y estrecha comunicación con Puno, que dentro de su escala representa lo más elaborado de la zona sur del Altiplano peruano. Puno constituye el centro o eje del área cultural de la Meseta del Collao, una de las áreas culturales más precisas y definidas dentro del panorama cultural peruano. Los otros grupos indígenas los consideran con respeto y los señalan como ejemplo, pues han logrado antes que muchos de ellos la propiedad de las tierras que cultivan por sus propios medios. Sin embargo, es interesante recalcar que Taquile en otros aspectos continúa siendo el grupo más conservador de las islas del lago y del área. Sus instituciones tradicionales 
guardan todavía mucho de lo que fue el pasado indígena así como de la influencia española de los siglos XVII y XVIII. Hombres y mujeres son extraordinariamente hábiles en el tejido. Los varones en el trabajo de la piedra y en la música.

Como el aprovechamiento de la tierra será siempre limitado, aún en las mejores condiciones, el crecimiento de la población agravará día a día su relación con la tierra. Este problema no puede resolverse en Taquile mismo y en forma incipiente han comenzado a salir en busca de otros medios de vida trabajando en las minas de San Antonio de Esquilache y otros lugares vecinos a Puno, tales como Juliaca e llave. En una segunda etapa han migrado a Tacna y Arequipa para trabajar en los campos agrícolas ocupando las plazas que dejan libres los campesinos que se vuelven obreros urbanos.Una tercera y última etapa en este proceso migratorio es la llegada de taquileños a Lima, por vez primera en $1954 .{ }^{1}$ Aún este grupo tan reducido y tan lejano siente la gran atracción que ejerce Lima, ellos han llegado y comenzado a trabajar como domésticos, con la finalidad de ahorrar para comprar tierras. Nada les tienta y gastan sólo en lo básico a fin de economizar al máximo debido a que tienen una sola meta: adquirir nuevas tierras. Más tarde ingresarán al engranaje del resto de campesinos que habita la gran ciudad.

Los diferentes cargos comunales que existen en la isla son tradicionales y si bien ella constituye el último de los ocho ayllu que componen el distrito de Capachica, Taquile está dividida en dos mitades o ayllu, cada uno con su Hilacata respectivo. Los Mandones, como en conjunto se denomina a las autoridades tradicionales, Alcaldes, Campo Alcaldes e Hilacatas, tienen clara conciencia de la dignidad del cargo y gozan de mucho respeto y consideración, debido a que son elegidos libremente en votación pública a mano alzada por todos los jefes de familia. A su lado existen las autoridades nacionales, todavía de menor prestigio: un Teniente Gobernador y un Teniente Alcalde, dependientes de Capachica, y un Sargento de Playa. El gobierno local está, pues, íntegramente en manos de sus autoridades tradicionales.

Existe el tipo de familia extensa, aunque de corta duración: se disuelve a la muerte del padre, dando lugar a la formación de familias nucleares hasta que se recomienza el ciclo. La descendencia se considera en la línea masculina con reconocimiento del parentesco materno. La ceremonia matrimonial es la religiosa, en las raras ocasiones que cuentan con la visita del párroco. Supervive el sirvinacuy, unión tradicional que precede al matrimonio católico.

Su complejo mágico-religioso y su concepción del mundo están íntimamente vinculados con los fenómenos de la naturaleza y con pautas tradicionales del grupo. La sequía, el rayo y el granizo son sus principales plagas. Ante estos fenómenos han mantenido y acomodado todo un complejo-mágico-religioso, mezcla de sus antiguas creencias y del culto católico incorporado. Una vez por año, al finalizar la cosecha, en marzo o abril, todos los isleños acuden a la cumbre de su cerro tutelar, Mulusina, a fin de rendir público culto a la pachamama (Madre Tierra), agradeciéndole por los frutos recibidos y pidiéndole sus favores para el año próximo. El culto es realizado en común por los "pacos" (magos benéficos), el mayordomo y el sacristán de la Iglesia.

Lo económico (recolección de los frutos) y lo sobrenatural (agradecimiento al espíritu de la tierra) están así íntimamente vinculados y, a su vez, actúan en la concepción que el taquileño tiene del mundo, profundamente telúrica, con una jerarquía entre lo conocido y lo desconocido y el sentimiento de dominio de lo sobrenatural, un sentido comunitario

1 Fondo Internacional para la Promoción de la Cultura, UNESCO, y Banco Internacional del Perú, Taquile en Lima. Lima, 1986. La experiencia de siete familias de migrantes a Lima está narrada en detalle en este libro. 
y gregario que las fiestas estimulan; un arte y una ciencia estrechamente vinculados a su realidad, a sus necesidades y casi siempre motivadas por lo mágico-religioso; un control social del grupo que actúa con fuerza, una prevención a la aceptación ciega de creencias, prácticas y ritos cristianos, total ausencia de holgazanes, mendigos, niños abandonados, viciosos, prostitutas.

Taquile es una verdadera comunidad indígena de campesinos, aún cuando no esté reconocida oficialmente. Ya no es una hacienda, ni sus habitantes son colonos. En 1957 son todavía indígenas representativos del nivel inferior del área cultural peruana de la Meseta del Collao y como tal un relicto o supervivencia de mucho de lo que fue el mundo prehispánico.

\section{La propiedad}

Uno de los aspectos más saltantes de la cultura en la Isla es la propiedad, dada la complejidad y conciencia que todo taquileño tiene de ella.

La tremenda lucha por la posesión de las tierras, agudizada en la década de 1930 a 1940 y que hoy tiende a solucionarse favorablemente al indígena, ha motivado que todos sus esfuerzos y anhelos estén pendientes de su logro, lo que por otro lado influye fundamentalmente en la estructuración actual del grupo. Su repercusión se deja sentir en todos las aspectos de la vida. En el aspecto económico constituye una liberación, no ser más colonos. Con tierras propias tienen asegurada una mejor posición humana y una solvencia básica, se trabaja mejor la tierra, se obtienen mayores rendimientos, lo que se traduce en una mejor dieta; sin hambre existen fuerzas que pueden dedicarse a otras labores. Durante buena parte del tiempo construyen botes, realizan intenso comercio con Puno, viajan sin temor por el bellísimo lago, todo lo que va dando mayor movilidad al grupo y produciendo ciertos cambios con la introducción de nuevos elementos culturales y valores, aunque con ciertas restricciones debido a su espíritu tímido y todavía conservador.

Asegurada la propiedad toda su organización social está sufriendo una remodelación, va estratificándose el grupo por ella, creándose el prestigio de unas familias sobre otras, formándose una nueva estratificación, que tiene marcada influencia en la organización interna y en las relaciones con el exterior. La intensa lucha por obtener títulos de propiedad los ha vinculado estrechamente con el conocimiento de los resortes judiciales que emplea la legislación peruana. Sus normas jurídicas tradicionales han sufrido un quebranto y van perdiendo así prestigio en la isla. Al aceptarse los procedimientos generales de la nación, la propiedad ha logrado en este aspecto incorporar este pequeño grupo al panorama total de la vida peruana.

La propiedad es así el aspecto más importante en la cultura de Taquile en estos momentos. Seguramente perderá tal carácter cuando acabe el reajuste que su introducción está produciendo. Entre la década de 1920 y la de 1940, el problema de la propiedad tiñó todos y cada uno de los aspectos de la vida del taquileño. Es un hecho que afectó y afecta toda la estructura del grupo. Para comprender mejor su funcionamiento, examinemos su trabazón pero, antes cabe presentar, a grandes rasgos, algunas apreciaciones generales sobre la situación a escala nacional.

Actualmente en el sistema de propiedad y en el trabajo se percibe un fenómeno de ajuste en todas las comunidades andinas del país. Están adquiriendo una peculiaridad propia, mientras que por un lado los patrones de la propiedad individual ya están bien establecidos, por otro perdura la fuerza de las pautas de ayuda mutua. Los conceptos de colectivismo correspondientes a la cultura antigua del Perú y del individualismo introducidos con la llegada de la cultura occidental, están siendo "reinterpretados" como señala Herskovits 
al definir este término: "como el proceso por el que los antiguos significados se adscriben a nuevos elementos o mediante el cual valores nuevos cambian la significación cultural de las viejas formas" (El hombre y sus obras, México, Fondo de Cultura Económica, 1952, p. 598).

La antigua organización comunal del trabajo subsiste en muchas comunidades para determinadas faenas como la siembra, cosecha, limpieza de las acequias, arreglo y construcción de caminos y de edificios (escuelas, locales públicos, etc.). Del mismo modo, en el régimen de la propiedad existen tierras comunales donde se construyen edificios públicos, parques, iglesias, escuelas, etc.; zonas de cultivo para las cofradías y para la comunidad misma o la escuela; y principalmente la gran propiedad comunal de las tierras de pastos situadas en la puna (3800 a $5000 \mathrm{msnm})$. La propiedad y el trabajo en las comunidades peruanas se presenta, pues, bajo estas dos formas: individual y colectiva. La propiedad individual de las familias comprende lo inmueble: tierras, viviendas, corrales y árboles; lo mueble: vestidos, utensilios, herramientas, productos agrícolas y semovientes. La propiedad corpórea ha mantenido su estatus aunque con mayor preponderancia individual. La propiedad individual es cuidada y trabajada por cada familia, combinándose el trabajo colectivo con este nuevo sistema en los casos arriba mencionados y con el reconocimiento de bienes inmuebles comunes.

En las comunidades costeñas, el panorama presenta variantes bien marcadas: los campesinos costeños son propietarios individuales de extensiones reducidas de tierra en medio de grandes haciendas. Lo comunal, lo colectivo casi no existe. Es el sistema individual el que norma su economía y la mayor parte de los campesinos son colonos o peones de los grandes latifundios.

En la selva, los grupos selvícolas están siendo desplazados por los colonizadores mestizos y dado su relativo nomadismo y su forma de trabajo, fundamentalmente de recolección y caza, presentan matices singulares. No tienen áreas precisas, ni propiedad de la tierra bien delimitada, y trabajan como "habilitados" por mercaderías o productos dentro de un sistema de explotación inicuo.

El colono mestizo en la selva puede ser comparado con el comunero mestizo de la sierra y la costa. El selvícola, el hombre de tribu, tiene un estatus propio dentro de la gradiente cultural peruana.

Claramente en Taquile se observa esta mezcla de formas. Los isleños son dueños de la vivienda que habitan; del canchón (pequeño terreno de cultivo alrededor de ella), de los árboles que la rodean, de animales y corrales a su lado, de tierras de cultivo diseminadas en pequeñas parcelas (andenes) en los seis "suyu" de la isla. Existen también tierras que son comunes para el usufructo de leña y pastos. Los "puquios" (manantiales) son considerados bienes comunes, así como también diversos edificios públicos. En el trabajo la ayuda común existe para diversas actividades. Han acomodado dos sistemas de propiedad y de trabajo con una marcada actitud cooperativista y de reciprocidad.

Pero en Taquile ya no existe propiedad comunal de las tierras de cultivo. Con la llegada de los españoles a la Meseta del Collao en 1533, la isla pasó a ser pertenencia del rey de España. En la segunda mitad del siglo XVI fue adjudicada por remate a Pedro González, pasando en los años siguientes y durante el siglo XVII de feudatario a feudatario, sea por nuevos remates, herencias o ventas. La familia Aparicio de 1656 a 1753. En los siglos XVIII y XIX los Cuentas, familia puneña, la explotaron como su hacienda considerando a sus moradores sus colonos. Esta propiedad única se subdivide en nuevas secciones llamadas "haciendas", disgregándose así la propiedad hasta llegar al presente siglo en que apenas subsisten pequeñas fracciones de una gran heredad en poder de dos ramas de aquella familia. 
Esta posesión de la tierra por extraños ha significado para los isleños un empobrecimiento cada vez mayor. El indígena de dueño absoluto de la isla en épocas anteriores al Estado Incaico y durante este, pasa bruscamente a colono, siervo de gleba, parte integrante, del suelo, siguiendo la suerte de éste, etapa que se prolonga hasta el presente siglo, con toda la secuela de abusos que bajo la denominación de "servicios personales de indios" subsiste aún en muchas comunidades andinas, el pongo, el kipu, el mitayo, el watacho, el ullaricuy, etc., que hacen de quienes los sufren víctimas inermes de una estructura económica y social que favorece a pocos.

Es sólo a partir de los últimos veinte años que buena parte de esta situación ha cambiado para la isla con la supresión del servicio personal de indígenas. Únicamente existen dos kipus con función de mayordomía, sin las características de explotación, como simple servicio voluntario de dos familias isleñas que pueden así utilizar parte de las tierras y cosechas en su propio beneficio; y un remanente de colonos para el trabajo de la heredad de la familia Cuentas constituido por unas veinte familias (17\%) que continúan tradicionalmente sirviéndolas en la cosecha y siembra de las tierras a cambio de una pequeña retribución en productos.

Por otro lado, el deseo vehemente del isleño de recuperar la tierra, ya que siempre la consideró suya, de ser dueño absoluto de ella con títulos saneados, ha sido logrado solamente después de innumerables vicisitudes en 1942, cuando se extendió la primera escritura pública de venta de tierras a un grupo de taquileños. En realidad, hasta esa fecha, el indígena no fue dueño de las tierras, pero sí un usufructuario de las mismas y este hecho de utilización ejecutiva de la tierra le confería ya un cierto acceso a la propiedad.

A diferencia de las otras islas del Lago, en que el cambio de cultura las va modificando rápidamente, la de Taquile, a pesar de su espíritu conservador, ha conseguido el mayor anhelo de todos los de su condición: ser los primeros dueños de sus tierras respaldados con documentos públicos.

Dueño ya el isleño de sus tierras, la propiedad está llegando a otra etapa: a la del acaparamiento de terrenos en manos de tres o cuatro indígenas acomodados que, a su vez, los venden o arriendan a los de inferior condición económica. Un catastro basado en un levantamiento topográfico en que se indique al detalle las diferentes parcelas de la isla a fin de que los isleños puedan indicarnos sus propiedades y utilización de la tierra, podría darnos cifras exactas de la parte de tierras que aún quedan en poder de los dueños de fuera, del acaparamiento que se está produciendo, de lo que cada familia posee y, lo más interesante, su distribución. Es sorprendente comprobar cómo va fraccionándose la pequeña propiedad, fenómeno también de gran trascendencia en el panorama de la propiedad en la sierra peruana. Hemos adelantado algo en esta labor al confeccionar el mapa geográfico de las diversas zonas de la isla, pero es sólo una pequeña parte, la tarea es larga y especializada y sólo nos queda consignarla como algo pendiente de llevarse a cabo, dada su trascendencia posterior.

Felizmente años después del trabajo de campo en la isla, 1950-52, y de la elaboración de este informe, en 1957, logramos una primera aproximación de un catastro elaborado por un maestro, el cual describimos al final del relato sobre el proceso de la propiedad.

\section{El proceso de la propiedad en Taquile}

La gentileza de los dueños foráneos, que nos han permitido revisar sus títulos de propiedad, muy bien conservados y con valiosos datos de su evolución desde el siglo XVI; las informaciones personales de muchos de ellos; las publicaciones con referencias para la isla y las notas de campo, nos proporcionan abundante material para conocer con bastante 
detalle el proceso histórico de la propiedad, aunque su análisis corresponde más al campo histórico. La familia Cuentas, por intermedio de la señora Antonina Cuentas y el doctor Enrique Cuentas, la familia Borda y el doctor Adrián Cáceres Olazo son los que han hecho posible este análisis, así como los isleños de Taquile y Amantani.

\section{Siglo XVI}

El primer dato histórico conocido hasta ahora es que la isla Taquile, junto con Amantani, fue rematada por el Rey de España Carlos V a su primer feudatario Pedro González de Taquila "de los primeros moradores del Collao" (Documento en el Archivo del Corregimiento de Chucuito, citado por Rómulo Cúneo Vidal en el Boletín de la Sociedad Geográfica de Lima, tomo XXXIII, 1917, pp. 359-69).

En la revisión cuidadosa de los cronistas de los siglos XVI y XVII casi no se ha encontrado ninguna referencia al nombre aborigen de la isla. La única mención precisa es la del padre Martín de Murúa, quien la denomina Taquilli (Historia del origen y genealogía de los Incas, Edit. Bayle, 1946, pp. 215-216). En la pp. 215 de esa obra dice:

"islas... la una Amantani, donde estaban indios y poblados y reducidos después de la visita general del Virrey Francisco de Toledo. Taquilli es la otra isla donde se adoraba otra guaca del mismo nombre; de suerte que todas estas islas tienen nombre por las huacas que en ellas se adoran, hay otras islas circunvecinas, otras dos islas de más nombre que otras pequeñas, que también tiene sus falsos dioses, más estas dos eran famosas".

El padre Murúa llegó al Perú en 1577, fue cura de Capachica y en 1590 escribió la obra que hemos mencionado.

El actual nombre de la isla puede provenir del apellido del primer feudatario, Pedro González de Taquila, el cual en boca de los isleños se transformó en Taquile, que es como ellos la designan y nosotros consignamos. La información histórica de su primer feudatario Pedro Gonzáles de Taquila, fue tomada al pie de la letra, es decir Pedro Gonzáles "de Taquila", creyéndose que con ello se le daba nombre a la isla, cuando en realidad se refería al lugar geográfico donde era feudatario, en este caso el nombre de la isla.

Mientras no se encuentren otros documentos, lo más probable es que Taquile provenga de Taquilli, como lo consignó Murúa (cura de Capachica por largos años), una huaca tal vez el nombre del promontorio más alto de la isla y donde ahora con el nombre de Mulusina realizan todos los años y en los momentos de crisis la ceremonia mágico religiosa más importante e imponente en ofrenda a la pachamama, la tierra y los huihuac que en ella habitan. Cuando le fue rematada la isla, el documento original debe haberse referido a que su primer feudatario Pedro Gonzáles lo fue de la isla Taquila, a la que el padre Murúa la mencionó como Taquilli, y con el tiempo denominada como Taquile.

También es interesante anotar que las dos islas, Amantani y Taquile, desde esa fecha aparecen estrechamente unidas en su evolución histórica, como tal vez lo estuvieron desde muchos siglos antes.

Los españoles llegaron a la Meseta del Collao en 1533 y comenzaron a establecer el orden colonial en ella durante las dos décadas siguientes, pero las continuas luchas entre los conquistadores permitieron que hasta la llegada del Virrey Francisco de Toledo, 1568, en muchas regiones del Perú continuara el régimen de la propiedad indígena. Con la reorganización de Toledo y sus reducciones; con la fundación de gran número de villas y pueblos y la composición de tierras es que recién fueron incorporadas grandes extensiones al nuevo sistema. Indudablemente que para Taquile el cambio debió operarse después de 1580 , época en que fue sacada a remate. 
Pedro González no tuvo hijos hombres, únicamente tres hijas mujeres las cuales se avecindaron en Arequipa (ref. Cúneo Vidal). Al no tener descendencia masculina es probable que sus pertenencias acabaran con su muerte.

\section{Siglo XVII}

El cinco de enero de 1604, estando en San Martín de Paucarcolla, el Juez de Venta y Composición de Tierras cumpliendo su cometido fue informado por los vecinos de lo siguiente:

“.. que a dos leguas del pueblo de Capachica por tierra firme y una por la laguna de Chucuito está la isla nombrada Amantani la cual ha sido informado que habría 30 años poco más o menos que visitando esta provincia el señor doctor Recalde, siendo Oidor de las Charcas, echó de ella los indios que allí había despoblándolas, haciéndoles derribar la capilla que tenían por no servirles... mas que para sus idolatrías, sacrificar y mochar el demonio y otras ofensas a nuestro Señor,.. y la declaró por realenga perteneciente a Su Majestad". (Doc. Borda).

Es decir, que si en 1604, Amantani fue despoblada, igual hecho debería haber pasado con Taquile, ya que su historia es paralela. Como ya hemos indicado, Pedro González al no tener herederos hombres también la habría abandonado a su población autóctona.

Desde 1604 hasta 1644 estuvieron abandonadas las islas y declaradas realengas; pero los isleños indudablemente continuaron viviendo en ellas, y si fueron arrojados su retiro debió ser muy temporal.

El 27 de mayo de 1631 el Rey de España expidió una Real Cédula que mandaba:

“... se vendiesen y compusiesen todas las tierras, vacas y cabras... que todas sean rematadas en el mejor provecho para la Real Hacienda... lo cual era necesario para ayudar los grandes gastos de los ejércitos en que se halla empeñada la Real Hacienda... para componerlas deben sacarse a vela y pregón al mejor postor..." (Doc. Borda).

Esta Real Cédula, fue recibida en Lima el 13 de julio o sea al mes y medio, e inmediatamente el Conde de Chinchón, Luis Jerónimo Fernández de Cabrera y Bobadilla, entonces Virrey del Perú, ordenó se celebrara un acuerdo general de hacienda que llegó a algunas conclusiones:

“... las tierras han sido vendidas, las más y mejores del reino... que es muy pequeña e infructuosa la parte que hoy podría venderse... que vendiéndose las tierras que hoy se juzgan vacas por falta y ausencia de los indios se cerrará la puerta a la reducción general... pero cumpliendo con lo ordenado se dan indicaciones para la composición y venta de tierras a los visitadores". (Doc Borda).

El primero de marzo de 1636 recién el Virrey ordenó se diese cumplimiento a la Real Cédula. Pero parece que la Orden no pudo cumplirse por diferentes circunstancias, organización, cambio de Virrey, etc., estando detenida hasta que el 23 de julio de 1643 el Marqués de Mancera, Pedro de Toledo Leiva, su sucesor decretó el cumplimiento de la mencionada Cédula Real:

"Por todos los caminos se debe prevenir que en el próximo año de 1644 sea cuando mayor fuera posible, especialmente habiendo de salir con alguna anticipación, según lo que para ello se ha escrito a los señores gobernadores de la Real Audiencia de La Plata y al señor Licenciado Blas Robles de Salcedo, Corregidor de Potosí... comunicándoseles el acuerdo real... se ha dado facultad con fecha 8 del presente al capitán Francisco Antonio de la Mazueca y Alvarado para que nombre alguacil y medidor.....este capitán recibirá 10 pesos ensayados cada día, 4 pesos el alguacil, 4 el medidor, 4 el escribano, los cuales se pagarán de lo que se beneficiare de las dichas tierras y puedan traer y traigan vara de justicia y mando a los corregidores de todas las ciudades, villas, lugares y repartimientos de indios..." (Doc. Borda). 
El primero de octubre fue nombrado por el Virrey, Antonio Fernández de la Cruz como Escribano de la Visita, y por el Visitador de la Mazueca fue designado Antonio de Franco de Urbina como alguacil. El medidor de la visita fue Bernardo Chacón.

Francisco Antonio de la Mazueca y Alvarado, capitán, tenía el siguiente cargo: Juez de Venta y Composición de Tierras de Paucarcolla, Chucuito, Pacajes, La Paz, Sicasica, Omasuyo y Larecaja.

El cuatro de octubre de ese año (1644) el Escribano de la Cruz salió de Lima para dar cumplimiento a su misión, lo acompañaron Pedro de Pedraza, Alonso Viscayno y Juan Gonzáles Mejía. En el Tambo de Mala, jurisdicción de la villa de Cañete, 13 leguas de Lima, el ocho de octubre, les dio alcance el capitán de la Mazueca Alvarado, el cual venía acompañado del medidor y el alguacil que habían salido el cinco. De esta manera los comisionados inician su viaje al Altiplano a cumplir su cometido.

El cinco de diciembre de ese mismo año, don Álvaro Félix de Vargas Mujica, contador de su Majestad, Juez Oficial de la Real Hacienda de la Paz, certifica que en el libro de Real Manual de su Real Contaduría, está asentada una partida en que se indica que ese día mandó a la Caja Real el Juez de Ventas y Composición de Tierras Francisco Antonio de la Mazueca, por intermedio de Juan Torres Salazar, corregidor de la ciudad; 1214 pesos 6 tomines y 3 gramos corrientes de a 8 pesos, por 734 pesos y 8 gramos ensayados de a 50 maravedis diciendo:

“....El peso que los entrega por la décima parte en el derecho real de media anata es de 7,348 pesos de la dicha plata ensayada que lo montan 334 días por el salario que trae señalado por sus oficiales en la comisión dada por el Virrey para la composición y venta de tierras de esta ciudad y sus cinco corregimientos y provincias de Chucuito los 240 días de los ocho meses de su ocupación y uso de la dicha comisión y los 94 restantes de venida y vuelta conforme al paraje.... a cinco leguas por día.... a razón de 22 pesos diarios por la comisión y mando ..... (334 días a 22 pesos diarios, 7,348 pesos de salario)" (Doc. Borda).

El 15 de diciembre el Juez de Ventas y Composición de Tierras está en Huancané y el cinco de enero de 1644 en San Martín de Paucarcolla, donde llega a tratar lo tocante a su comisión. Concurren los vecinos de Capachica, Coata y demás pueblos cercanos a este y allí recibe la información que ya mencionamos sobre la visita de Recalde a Amantani, su despoblamiento y su declaración de realengas, perteneciente al Rey de España. En vista de estas declaraciones ordena sea sacada en almoneda y que se den 30 pregones para que se remate la isla de Amantani a quien diere más, en el término de tres días, admitiéndose posturas y pujas.

El seis de enero de 1644 se da el primer pregón en la plaza principal del pueblo de Paucarcolla, ofreciendo en venta la isla de Amantani, en presencia del Juez de Ventas y los vecinos notables de él y de los pueblos cercanos. Terminado el primer pregón se repitieron cuatro más. Al quinto pregón se presentó la petición de Pedro Sotomayor Vivanco, en la que hace la primera postura a la isla, perteneciente a la jurisdicción de Capachica, ofreciendo 1000 pesos corrientes de a 8 reales a pagar el próximo año de 1645 , siendo su fiador Juan José Rodríguez del Campo.

“... La dicha isla con todos sus pastos, aguadas, tierras de sembrar, paredones del tiempo del Inca como en ella se está sin reservar cosa que sea tocante a ella por tierras de Su Majestad, como V. M. lo tiene declarado por no servirles a los indios de dicho pueblo y estar como está más de 4 leguas de Capachica las dos de tierra y las dos de agua, para cuya embarcación es menester barco de cubierta por las grandes olas que se levantan con los vientos, con que los dichos indios Capachica los despoblaron mucho tiempo ha..." (Doc. Borda). 
La postura es admitida y se ordena continúen los pregones. El seis y siete de enero se dieron 24 pregones más.

El ocho de enero, Pedro Pacheco de Chávez, residente en la provincia presenta su postura, haciendo puja a su favor:

“... Con calidad para poder fabricar casas, ranchos y bodega en los pastos, en la misma forma que la tiene puesta Pedro de Sotomayor en la pequeña que está junto a la nombrada TAQUILA y pone en 4,000 pesos de a 8 reales que pagará en la Real Caja de la ciudad de La Paz, los dos mil para fin de febrero de 1645 y los otros dos mil para fin de febrero de 1646, para lo cual haciéndosele el remate dará fianzas y otorgará escritura en forma con días y salarios, y a ello obligó su persona y bienes habidos y por haber..." (Doc. Borda).

Enseguida se dio el último pregón refiriéndose a la postura de 4000 pesos.

El nueve de enero de 1644, en el mencionado pueblo de Paucarcolla y en la plaza pública, el capitán Francisco Antonio de la Mazueca y Alvarado, Juez de Visita, Venta y Composición de Tierras:

“... en presencia y con asistencia de muchos españoles y de Pedro Pacheco de Chávezy Pedro Sotomayor Vivanco, personas que tienen hechas posturas a la isla de Amantani, por voz de Cristóbal Vario Negro, pregonero, se trajo en venta y pregón la dicha isla en la forma que la tiene puesta Pedro Pacheco de Chávez que es con la islita pequeña que está junto a ella nombrada TAQUILA y con calidad de poder hacer casas, ranchos y bodegas todas las que fueran necesarias para embarcar y desembarcar los frutos de dicha isla y lo que se hubiere a llevar a ella, las cuales dichas casas, rancho y bodega se han de hacer en tierra firme en el puerto que fuere más a propósito para embarcar y desembarcar así de los usados y descubiertos hasta ahora como en lo que adelante se descubrieren sin que ninguna persona se lo impida y el dicho pregonero dijo que está puesta la dicha isla con las calidades referidas en cuatro mil pesos de ocho reales pagados la mitad a fin de febrero del año que viene de $1645 \mathrm{y}$ los dos mil restantes para el año siguiente de 1646 que si hay quien puje parezca que se ha de rematar luego en quien más diere y aunque hizo muchos apercibimientos no pareció quién pujase por lo cual y por mandato del dicho juez dijo a la una, a las dos y a la tercera que buena y verdadera pues que no hay quien puje ni quien diga más que buena, que buena pro le haga, con lo cual quedó hecho el dicho remate y estando presente el dicho Pedro Pacheco de Chávez lo aceptó según y como en él se contiene y se obligó a pagar los dichos cuatro mil pesos en la forma y a los plazos referidos con la calidad de que si en alguno de los dichos plazos no pagare la cantidad que tiene obligación, los oficiales reales pueden enviar a la parte donde estuviere una o más personas a la cobranza de lo que debiere pagar con seis pesos de plata ensayada de salario en cada un día de los que se ocuparen en ida, estada y vuelta para lo cual hipotecará la misma isla con todo lo que en ella se fabricare y ganado que pudiere para lo cual dará fianzas en forma y a su cumplimiento obligó su persona y bienes habidos por tal y dio poder a la justicia de su majestad y en especial a los dichos oficiales reales para que a ello le apremien como por sentencia pasada en cosa juzgada y como por maravedis y haber de su majestad y el dicho juez dijo que en nombre de su majestad y en virtud de su comisión aprueba este remate y daba y dio título al dicho don Pedro Pacheco de Chávez de las dichas islas en la forma y con las calidades aquí contenidas con condición que dentro de seis meses saque confirmación del gobierno donde no pasado quede vaco lo susodicho y lo en ello fabricado y se pueda vender por de su majestad para lo cual se le de el testimonio en forma con la comisión de su excelencia por cabeza y ambos los firmaron a quien doy fe conozco, etc. El Licenciado Julio del Salto cura de este pueblo, Pedro Ramírez y Bernardo Chacón, presentes, don Pedro Pacheco de Chávez, don Francisco Antonio de Mazueca Alvarado. Ante mí Antonio Fernández de la Cruz, escribano de su majestad. En Paucarcolla en 9 de enero de 
1644 yo el escribano notifiqué lo contenido en el remate antecedente en cuanto a la confirmación del gobernador a don Pedro Pacheco de Chávez en su persona de que doy fe ante mi el escribano de su majestad" (Doc. Borda).

Es así como desde 1644 Taquile pertenece, nuevamente, a título legal, a un segundo feudatario. También es interesante anotar cómo la isla entra en el remate como un anexo de la de Amantani, que es más grande y por lo tanto de mayor importancia económica. En este documento el nombre que se consigna es Taquila, lo que no sucederá en los posteriores en que unas veces es llamada Taquili y otras Taquile. Se hace mención a la estrecha vinculación de las islas con Capachica, lo que sucede hasta el presente, en que ambas islas son consideradas como el último ayllo de Capachica y políticamente según la organización del país pertenecen a su jurisdicción. El puerto que promete construir el rematista fue el de Campanario, en Capachica.

El cinco de junio del mismo año el Juez Oficial de la Real Hacienda de La Paz manifiesta que Pedro Pacheco de Chávez llevó a esa Caja Real 153 pesos corrientes de a 8:

“... por tantos que montó el dicho real de media anata del precio en que compró las dos islas en la laguna de Chucuito ... cuya venta se hizo conforme al arancel real y de la nueva orden de su majestad en que se incluyen 3 pesos de ellos por la llevada hasta la ciudad de los Reyes..." (Doc. Borda).

El 19 de abril en Lima, se ordena, visto el expediente elevado por Pedro Pacheco de Chávez, se le despache título y confirmación de propiedad en forma ordinaria.

El Fiscal Protector de la Real Audiencia de Lima informa también sobre el expediente, manifestando que:

“... habiendo visto los autos de venta de dichas tierras y mientras los indios les informen del despacho que tienen a ellas o si les han dejado las que han menester contradice dicha venta y a mayor abundamiento apela de ella para ante quien deba y protesta no les pare juicio ni la confirmación a que pretende..." (Doc. Borda).

En las disposiciones que la Corona de España daba para la venta y composición de tierras se precisaba claramente que siempre que hubiera indígenas en las tierras a vender, debía respetárseles el derecho de poseer tierras para sus cultivos y pastos a fin de que tuvieran con que subsistir.

El Fiscal Protector de los Naturales tenía la misión de velar por el cumplimiento de tal disposición y siempre tenía que observar toda venta hasta que se cumpliera lo establecido. Este reconocimiento tuvo grandes proyecciones y es interesante destacar el hecho de que muchas veces los indígenas lo supieron y consideraron como un derecho de propiedad que en parte así lo ha sido para su propiedad básica. También el no reconocimiento de este derecho ha ocasionado muchos abusos y quejas del indígena. Esto lo veremos más adelante.

El 31 de junio de 1644 se realizó una de las primeras visitas a las islas Amantani y Taquile. El Capitán Francisco de la Mazueca, después del remate en Paucarcolla y para dar posesión a su nuevo dueño, hizo en las islas su "mapada", es decir un reconocimiento geográfico donde se precisaron los linderos de los "suyo" y la ubicación de sus diferentes lotes. Hecho esto según la costumbre de la época se dio posesión al feudatario. (Datos en documento Cáceres Olazo y documento isla de Amantani, inscritos en la Notaría de Luis S. Ponce R. en Puno el 15 de febrero de 1950). Las referencias precisas sobre esta visita desgraciadamente no hemos podido consultarlas. El documento de Amantani no es muy claro porque sólo pudimos ver una copia a máquina que tenía muchos errores. Este documento fue encontrado por los isleños en un caserío de Capachica después de una búsqueda paciente de varios años, dado que sabían de su existencia y al igual que los de Taquile lo consideraban como un título de sus antepasados para justificar que la isla les pertenecía. 
El ocho de agosto de 1644 el Virrey Marqués de la Mancera, confirma y aprueba a Pedro Pacheco de Chávez en la propiedad de las islas otorgándole título definitivo de ellas.

"...cuan firme y bastante de derecho se requiere para que siendo sin perjuicio de tercero las tenga y posea él y sus herederos y sucesores y como cosa suya propia habida y adquirida con justo y legítimo título comprada con sus propios dineros las pueda vender, dar, donar, trocar, traspasar, enajenar y hacer de ellas lo que quisiere o por bien tuviere con los pastos, montes y aguas de las dichas tierras han de ser y sean comunes como su majestad lo tiene ordenado y al corregidor del partido y a otros cualquier justicia le den y hagan dar la posesión de dichas islas sin consentir que de ellas sea desposeído sin primero ser oído y por fuero y derecho vencido y lo cumplieran así pena de cada quinientos pesos de oro para la cámara de su majestad y dará la razón el Tribunal de Cuentas. Fecha en el Callao el 8 de agosto de 1644..." (Doc. Borda).

El 24 de julio de 1647 Pedro Pacheco de Chávez cancela en la Real Caja de la Ciudad de La Paz el valor de compra de las islas.

Es así como desde 1644 hasta 1654 es propietario de Taquile Pedro Pacheco de Chávez, su segundo propietario "miste".

El 29 de mayo de 1654 se lleva a cabo la segunda visita a la isla Amantani. El Juez Visitador fue Fray Pedro de Velasco, de la orden real de Redentores de Nuestra Señora de La Merced, Comisario y Calificador del Santo Oficio, "por la suprema y general inquisición", Francisco Fosón fue el intérprete, Gaspar de Loayza el defensor de indios, Alfonso Pizarro el mediador y Juan de Mesta el escribano público de la provincia de Paucarcolla. La visita correspondió a los pueblos del Collao y la isla Amantani debido al reclamo de su población indígena "sobre venta y composición de tierras y del agravio de los indios", su finalidad fue hacer una nueva medición de Amantani y restituir las tierras de los indios. Concurrieron indios caciques y principales de los pueblos de Atuncolla, Coata, Huata, Capachica, Caracoto, isla Amantani e isla Taquile. De esta última fueron Presentación Aparezio, cacique, Juan de Dios Huata y Masco Cruz, hilacatas, dato de gran interés e importancia.

Una de las ramas actuales de los Huata manifiesta que este Aparezio o Aparicio fue el tronco de su origen, el abuelo que perdió los títulos de propiedad de la isla que ellos afanosamente buscaron y aún piensan en su existencia, afirmando que están en la Iglesia de Copacabana (Bolivia). Este informe lo consignamos en nuestras notas de campo en 1950 antes de que los de Amantani descubrieran el documento que nos sirve para esta relación y que vino a confirmar el relato oral. El apellido Aparicio va a jugar un papel principal en Taquile más adelante. Actualmente ya no existe ese apellido, pero los de Cruz y Huata sí. Lo que no hemos podido averiguar es cómo esta familia Aparicio, que por intermedio de Presentación concurre a esta visita como cacique de Taquile, después aparece en 1656 como dueña de la isla hasta 1753 (casi un siglo). Cabe suponer que haya sido un mestizo, hombre de confianza de Pacheco de Chávez y quien se ganó, igualmente, la confianza de los taquileños a extremo de considerarlo uno de los suyos. No es posible imaginar que fueran indígenas porque obtuvieron títulos y uno de ellos heredó solares en Arequipa, cosa vedada en esos tiempos a los indígenas. Lo probable es que Pacheco de Chávez les dejara a ellos el cuidado de la isla y como "ladino en lengua castellana" fue a defender los derechos de los isleños como su cacique en la visita a Amantani en 1654.

En el relato de la visita hay valiosos datos sobre la distribución de los suyo en Amantani, la posesión de las parcelas con sus nombres originarios, en su mayoría de origen quechua y pocos aymara que concuerdan exactamente con los actuales. En una parte dice: 
“...está ubicada a tres leguas de distancia del este de Capachica, según vista de ojos en ella pueden embarcar y desembarcar únicamente balsas de totora en todo tiempo ... tiene 539 cordeladas o sea 12,605 brazas de largo ... y está ubicada en la laguna grande Chucuito...".

Como hemos manifestado anteriormente, el objetivo principal de la visita fue constatar la utilización de la isla por Pacheco de Chávez que la adquirió en la visita anterior, quien parece que no cumplió con las prescripciones legales establecidas en su adjudicación, ya que según dicha compra debía reservar parte para los indios, tierras para pastos y para cultivos, lo cual motivó el reclamo de los isleños por los abusos del feudatario. Además dijeron que las mediciones no fueron hechas en presencia de los indios, "vista de ojos, ni mensuras...". Ante esta queja el Visitador, ya en la isla de Amantani, ordenó se presentase el propietario a rectificar los sobrantes de la medición y el respeto a las tierras de los indios, ordenando que debía componerse los defectos de los títulos y que si en el término de dos días no se presentase "se sacarían a pregones y nuevo remate..." (Doc. Isla Amantani). Cuando el Visitador dictó la sentencia definitiva estaba presente Pedro Pacheco de Chávez (Doc. Isla Amantani).

Hasta esa fecha la isla Taquile no tenía gran interés para su dueño, lo prueba este reclamo de Amantani en el cual ya desde esa época los conflictos de tierras siempre alcanzaron caracteres alarmantes. No se dice nada de Taquile y sólo se consignan los nombres de las autoridades que concurrieron al reclamo de los amantanenses. Ya hemos relatado cómo fue efectuado el remate de Taquile: como "una islita pequeña", su mayor lejanía, su menor extensión de tierras y su reducida población no ofrecían problemas a su dueño, el cual parece que no la controlaba directamente. También se colige que hasta esa fecha ninguna de las dos visitas llegó a Taquile. La lucha entablada por la defensa de la propiedad en las dos islas comienza según estos datos desde la posesión por Pacheco de Chávez y gradualmente va adquiriendo fuerza y fue motivo de preocupación constante en la vida de los isleños, al extremo de que por siglos, desde 1644 hasta 1942, dependieron de su solución. Hecho lógico para el indígena y tiempo durante el cual la tensión fue in crescendo, unas veces con violencia y otras solapadamente.

En 1656 o sea dos años después, aparece Andrés Aparicio como propietario de la isla (Doc. Cáceres Olazo). Ya hemos indicado las suposiciones de este paso. Desde esta fecha hasta 1753 los Aparicio serán los dueños de las dos islas, del puerto de Campanario en Capachica y de otras tierras en la mencionada península.

\section{Siglo XVIII}

El 30 de octubre de 1692 el Rey de España expide una Real Cédula ordenando el arreglo y el ajuste de las propiedades de la Corona, a fin de aumentar los ingresos de la Real Hacienda, debido a que el próximo año debían hacerse muchos gastos en los ejércitos y otros extraordinarios:

“... debe ponerse cobro en lo que se estuviera debiendo por causas de compra de villas, lugares, dehesas, tierras bosques, plantíos, alcabalas, rentas, pecho o derechos otra cualquiera cosa que se haya enajenado de la corona por razón de ventas ... todo de acuerdo a mi real decreto de 15 de setiembre de este año ..." (Doc. Borda).

El plazo que dio el Rey de España para cumplir estas disposiciones en el dominio de las Indias fue de dos años, para los reinos de Castilla y Aragón seis meses y para el reino de Italia un año. Sin embargo, posteriormente un nuevo Decreto Real de 15 de octubre restringe esos plazos. En otra parte dice:

“...los que no tengan títulos ni justas causas para ocupar tierras de mi patrimonio, contraviniendo cédulas contenidas en el libro $4^{\circ}$, Título 12 de la Nueva Recopilación 
de Indias, deben ser nuevamente compuestas para lo que faculto a los Virreyes, Presidentes y Gobernadores hagan nuevos remates al mayor postor ..." (Doc. Borda).

Es sólo el 15 de agosto de 1707 que el Rey designa a Bernardino de Valdez como su Delegado para dar cumplimiento a la Real Cédula de 1692. El 6 de febrero de 1711, igualmente en Madrid, se nombra a Clemente Díaz de Durana, Decano de la Audiencia de Charcas, como Subdelegado para el cumplimiento de la Real Cédula y por su falta o ausencia a Juan Bravo de Rivero, oidor de ella y en tercer lugar a Gregorio Núñez de Rojas. El 1 de octubre de 1714 se excusa de la comisión Clemente Díaz de Durana, radicado en La Plata e igualmente Juan Bravo de Rivero delega la comisión en don Francisco Ramírez de Arellana. Pero como la gran zona que le toca visitar es muy extensa para él, en Irupana (Bolivia), el ocho de julio de 1716 subdelega la comisión en la persona de Mateo Suero Gonzáles para que se encargue de las provincias de Lampa, Azángaro y Paucarcolla. El 3 de septiembre en Coroico de las Yungas Chapes (Bolivia), el licenciado Juan Bravo de Rivero ordena que Mateo Suero pase rápidamente a visitar las provincias que se le han asignado y en el término de 300 días las recorra y mida:

"...componiendo con los poseedores las que lo necesitaren por defecto de título, confirmación o demasías para lo cual pedirá personalmente a dichos poseedores y hacendados los títulos y demás instrumentos en cuya virtud las poseen y conforme a ellos hará la mesura y las demasías que por ella hallare como también las tierras que por cualquiera suertes se estuvieren poseiendo sin título de parte de su majestad, pondrá en su real patrimonio caso de no querer componerse sobre ellas los poseedores, y sacará en almoneda pública y rematará en el mayor postor procediendo los pregones y demás requisitos dispuestos por derecho en almonedas de haciendas, real y de querer, componerse los poseedores, los admitirá al mejor y más acomodado convenio y composición que se pueda sin agravio ni molestia de partes atendiendo siempre con el mayor cuidado posible a los indios de modo que no reciban vejaciones ni injusticia por lo que toca a las tierras del común de sus pueblos, como del particular de cada uno procurando que las ventas que hiciere sea por su justo precio y verdadero valor y así éstas como las composiciones de contado, remitiendo a su merced, el señor juez, el producto de uno y otro con cuenta y razón a la mayor brevedad y seguro necesario, en las ventas y composiciones cuyo valor no excediere al de 200 pesos corrientes eximirá a las partes del gravamen de ocurrir por más aprobación que la de su auto en atención a la distancia que hay de dichas provincias a la Ciudad de los Reyes y en este caso cobrará juntamente por el derecho de la media anata el $5 \%$ de lo que montare la renta y composición y despachará los títulos y demás recaudos necesarios para en guarda del derecho de las partes que compusieren o compraren dichas tierras nombrando medidor de su satisfacción, alguacil y escribano si lo hubiere y en caso de no haberlo o no ser aunque lo haya de su confianza..." (Doc. Borda).

Estas instrucciones que se ciñen exactamente a los trámites establecidos en la legislación de la época para la venta y composición de tierras nos permiten apreciar a través del caso concreto de Taquile, la forma cómo eran realizadas estas comisiones en las posesiones españolas de América del Sur en los siglos XVII y XVIII.

El 22 de enero de 1717 desde La Paz, Juan Bravo de Rivera, de acuerdo a una carta del Visitador Mateo Suero, pide ampliación del plazo de la visita en 150 días más. Un nuevo pedido de 100 días más hace el 10 de diciembre y el tres de abril de 1718 solicita otro plazo de 60 días.

En mayo de 1718, el Visitador se encuentra en San Salvador de Capachica, después de haber hecho las proclamas de su visita en Paucarcolla, a fin de que todos los hacendados dueños de tierras y estancias comparezcan con sus títulos "y demás instrumentos en cuya 
virtud los poseen" para de esta manera visitarlas. Entre los muchos que se presentaron lo hizo el capitán Joseph de Aparicio “por sí y en nombre de los demás interesados, dueños y poseedores de la isla de Amantani y de otra pequeña llamada Taquili” (Doc. Borda). Haciendo, a petición del visitador, la información de que poseían dichas propiedades en forma legal, manifestando los títulos y presentándolos en debida forma. Según dichos títulos las islas fueron compradas en almoneda pública por Pedro Pacheco de Chávez a su Majestad y en su real nombre a Francisco de la Mazueca y Alvarado, visitador de las tierras "que fue de esa provincia en 4,000 pesos corrientes que se pagaron a las reales cajas de la ciudad de La Paz el 24 de julio de 1647 ....cuya propiedad fue confirmada el 8 de agosto de 1644 por el virrey..." (Doc. Borda). Repite exactamente los datos mencionados en el anterior expediente del que recogimos la información del siglo XVII y viene a confirmar, más de 70 años después, la veracidad de tales informaciones.

Hecha la presentación, el capitán Aparicio pide que vistos por representantes de $\mathrm{Su}$ Majestad los títulos de propiedad, se sirva aprobarlos por corrientes y sin defecto alguno y en su virtud amparar a él y los demás interesados en la posesión y propiedad de las islas “... para lo cual servirá a V. Majestad por derecho de donativo con 30 pesos corrientes...”.

Esta es la segunda referencia concreta de que las islas estaban desde 1656 en poder de la familia Aparicio. El hecho de que el capitán Aparicio presentara los títulos en que constan el remate de las dos islas a Pedro Pacheco de Chávez, está indicando que el paso de la propiedad pudo haber sido por donación o por traspaso de los derechos. Esto último parece probable porque estaba de acuerdo con las disposiciones reales que decían "... puede ceder, donar, vender, trocar, traspasar, enajenar y hacer de ellos lo que quisiere..." (Disposiciones en la confirmación de ocho de agosto de 1644 por el Virrey Marqués de la Mancera). Y la confirmación posterior del 12 de mayo de 1718, hecha por el subdelegado Mateo Suero y Gonzáles, les confirma legalmente este derecho. Esta confirmación se realizó inmediatamente después de la petición del capitán Aparicio, en el mismo pueblo de Capachica, provincia y corregimiento de Paucarcolla, según la cual el visitador "aprobó según como dichos títulos se convienen y en su virtud amparó en la posesión y propiedad de la isla de Amantani y la pequeña nombrada Taquili al capitán Joseph de Aparicio y demás interesados, con el puerto, bodegas, ranchería y tierra firme.... para que siendo sin perjuicio de tercero que mejor derecho tenga no sean desposeídos sin primero ser oídos “... mandando así mismo se siente la partida en el libro de visitas de los 30 pesos que exhibe de contado por derecho de donativo... y se le devuelvan los títulos originales que presentó con testimonio de los nuevamente actuados en la visita" (Doc. Borda).

La familia Aparicio es así la tercera propietaria de la isla Taquile desde 1656 hasta 1753. En este año, al morir Salvador Aparicio, la propiedad de las islas que quedó indivisa entre él y sus dos hermanos Andrés y Joseph, comienza a ser vendida por sus herederos a María Rosa Bravo de Núñez, mujer de Silvestre de las Cuentas y Valdez. Esta señora, pacientemente, desde esa fecha y hasta su muerte en 1787 ó 1790, va adquiriendo poco a poco todas las acciones de los herederos para de esta manera dar origen, ya a fines del siglo XVIII, a la propiedad exclusiva de los Cuentas.

Veamos al detalle cómo se realiza este paso de la propiedad de la familia Aparicio a la familia Cuentas en la segunda mitad del siglo XVIII.

Los Aparicio fueron tres hermanos: Francisco, José y Juan. Este último tuvo tres hijos: Salvador, Andrés y Joseph. Parece que Andrés fue el que recibió la propiedad de Pedro Pacheco de Chávez en 1656. Joseph debe ser el capitán que se presentó a confirmar sus derechos cuando la visita de Mateo Suero y Gonzáles en 1718. En 1728 este Joseph vendió sus derechos a su hermano Salvador, mediante una escritura "Guarentigia", hecha en 
Chucuito, en 800 pesos, venta que sus herederos no reconocieron y por lo cual entablaron juicio a los herederos de Salvador. Andrés, el otro hermano de Salvador, también cedió su parte de acuerdo a una sentencia de la Real Justicia de Puno en juicio contradictorio por 1,000 pesos que gastó Salvador en el seguimiento de un pleito y defensa de un solar y casas que tenían en la ciudad de Arequipa. Como compensación de ese gasto y de la parte que le tocaba en la herencia Andrés se fue a Arequipa y Salvador quedó dueño de sus acciones en las islas. De esta manera Salvador, hasta su muerte en 1753, se convirtió en casi el dueño absoluto de las islas y el puerto. Pero, como la propiedad estaba indivisa, había herederos de sus tíos Francisco y José que reclamaban su parte, así como los que no aceptaron la venta de su hermano Joseph. En estas circunstancias muere Salvador Aparicio quien tuvo cuatro hijos: Juan, Blas, Lorenzo y Estefanía.

El mismo año de su muerte sus hijos Juan y Estefanía realizan la primera venta de la familia Aparicio a los Cuentas.

El 18 de enero de 1753 venden a Juan Antonio Bravo de Saravia vecino de Puno, azoguero, dueño de minas y socavones reales:

“... la parte que a cada uno de nos los otorgantes nos toca y pertenece de la herencia patrimonial y legítima en las dos islas de Amantani y Taquili, que están en la gran laguna nombrada de Chucuito perteneciente a la jurisdicción y doctrina de San Salvador de Capachica... tierras de sembradío de papas, quinua y demás frutos ... más caseríos, aguadas, pastos de ganado mayor y menor, ahijaderos, potreros, canchas, corrales... todo, indiviso desde la muerte de nuestro abuelo Juan Aparicio ... tablones cultivados y por cultivar, cerros, montes y más lugares que nos toca, compradas y compuestas con su majestad ante sus jueces mensurarios confirmado por el real y superior gobierno de estos reinos, cuyos títulos e instrumentos paran en poder del dicho nuestro hermano Blas de Aparicio, que como uno de los coherederos los recogió por muerte del dueño, nuestro padre, según y como nos tocase y perteneciente por hijuela al tiempo de la división y partición por libre de censo, carga, empeño, hipoteca especial. . . en 333 pesos corrientes a cada uno o sea 666 que nos ha dado y entregado en plata sellada Juan Antonio Bravo de Saravia, para el efecto de nuestra manutención y alimentos de nuestras obligaciones por la inopia en que nos hallamos...." (Doc. Borda).

Es así como de cuatro acciones de Salvador dos pasan a poder de Juan Antonio Bravo de Saravia, que como veremos más adelante es el padre de María Rosa Bravo de Núñez.

En la misma fecha (1753) Juan y Estefanía venden también en igual suma, 666 pesos, el derecho y parte que les tocaba y pertenecía como coherederos con sus hermanos de la herencia de su tío Andrés, que como ya hemos mencionado, fue adquirida por Salvador Aparicio, su hermano (o sea 2 acciones de 4 que pertenecieron a Andrés Aparicio). Y en la suma de 400 pesos, igualmente, ambos hermanos venden la parte que heredaron de su otro tío Joseph, por venta que hizo éste a su padre Salvador en 1728, pero

“... como sus herederos a pesar del dilatado tiempo de posesión en que estaba nuestro padre ... han movido pleito rescindiendo el contrato ... motivo por el cual el litigio del cual tenemos amplio derecho por ser venta y traspaso legítimo, la damos en venta y traspasando los derechos de evicción y saneamiento que tenemos contra dichos herederos de Joseph ..." (Doc. Borda).

Dos acciones del tío Joseph pasan también a Juan Antonio Bravo de Saravia. El total de la venta fue por 1732 pesos. La escritura fue hecha en la ciudad de San Carlos de Puno, ya para esta época Paurcarcolla había perdido importancia y Puno comenzaba a ganar la suya. Es así como el padre de María Rosa Bravo de Núñez efectúa por cuenta de ésta y con dinero de ella la primera de una serie de adquisiciones, el 27 de octubre de 1757, o sea cuatro años después de que Juan Antonio Bravo de Saravia se presentara ante el Corregidor, Justicia Mayor y Alcalde Mayor de Minas y Registros Reales de Puno declarando: 
“...que la compra que hizo de tierras por valor de 1,732 pesos, es perteneciente a María Rosa Bravo de Núñez, mujer legítima de don Silvestre de las Cuentas Valverde Niño de Guzmán, con cuya plata que le entregó exequible en la expresada cantidad las compró de su pedimento y ruego ..." (Doc. Borda).

De esta manera, queda aclarada la comisión del padre y la señora Bravo de Núñez agrega un nuevo título a sus compras de tierras.

Un año antes, el tres de junio de 1756, ella por su propia cuenta, compró a la viuda de Lorenzo Aparicio su acción en 670 pesos. Sebastiana Valencia la viuda, al hacer la venta expuso:

“...vendo porque la dicha cuarta parte en nueve años que ha que el dicho mi marido murió, no nos ha reportado un grano de frutos para nuestra manutención mayormente para la indispensable paga del funeral y otros muchos empeños que dejó causados ... y sólo los demás coherederos, especial mi cuñado Blas Aparicio se han aprovechado y utilizado con siembras sin permitirme en dilatado tiempo a que haya entrado a hacer mis cultivos y siembras para nuestros alimentos... por hallarme mujer sola, desvalida e imposibilitada de pasar a reconocer dicha parte por el riesgo tan manifiesto que hay en el tránsito preciso por la laguna en embarque en distancia de más de 12 leguas, por estas razones he tenido por conveniente vender dicha acción para con su producto alimentarnos" (Doc. Borda).

Sebastiana tuvo dos hijas Nicolasa y Gregoria, herederas de la cuarta parte. Gregoria murió y la heredera fue la madre de ésta, de manera que ella y Nicolasa, su hija, eran las dueñas de una acción. Esta fue la primera compra de la señora María Rosa Bravo de Núñez de las Cuentas.

El mismo día en que el padre declaraba que había comprado las acciones de Juan y Estefanía Aparicio por cuenta de su hija, ella llevaba a cabo una nueva adquisición. Los albaceas de Blas de Aparicio (Joseph de Saes, Gabriel Orejón y Juan Eusebio de Jiménez) extendían una escritura de venta a favor de la señora Bravo de Núñez por la parte que poseía su depositario en las islas Amantani y Taquile, en la suma de 660 pesos. En la venta fueron incluidas 148 cargas de papas de semilla, dos yeguas, un caballo y una potranca de año y medio, se manifestó "que las tierras lo fueron heredadas de su padre Salvador y éste de su abuelo Juan, con cuyos herederos están indivisas y por partir con la parte de las caserías, aguadas, pastos de ganado mayor y menor, ahijaderos, potreros, canchas, corrales y tablones cultivados y por cultivar, cerros, montes y más lugares que le perteneció comprados y compuestos ante sus jueces mesurarios... ". Entró también en la venta la acción que le correspondía por parte de su tío Andrés. También se anotó que Blas de Aparicio había recibido ya la mitad de lo estipulado antes de morir y que restaba la otra mitad solamente como cancelación. Esto sucedía el 27 de octubre de 1757.

Con esta compra la señora María Rosa Bravo de Núñez terminó de adquirir toda la herencia de Salvador Aparicio que estaba fraccionada en sus cuatro herederos, casi toda la herencia del otro hermano Andrés, aunque aquí hay un pequeño vacío, pues Sebastiana al vender su parte no hace mención de esta herencia como lo hicieron los otros dado que tenía igual derecho. Parece que ella como no podía ir a la isla Blas Aparicio le administraba con gran abuso su heredad, por lo cual es probable que Blas la incorporase a su heredad. El hecho es que toda la propiedad de los dos hermanos Aparicio, Salvador y Andrés, pasa íntegramente a la nueva dueña. Del tercer hermano Joseph no sucede lo mismo porque, como hemos señalado, sus herederos desconocieron la venta que hizo su padre a favor de su hermano Salvador, aunque la señora Bravo de Núñez compró dos acciones de cuatro correspondientes a Joseph. Para ser dueña absoluta de la isla le faltaba ganar este pequeño juicio ya seguro para ella y lograr así lo más importante, la compra a los herederos de los 
dos hermanos de Juan, o sea Francisco y José, y como había pasado tanto tiempo ellos eran más numerosos, aunque por otro lado la fracción que poseían era muy reducida.

Meses antes de todo este arreglo, que fue en octubre de 1757, la señora María Rosa Bravo de Núñez de los Cuentas eleva en abril del mismo año un pedido manifestando ser dueña de tierras en las islas Amantani y Taquile y en Puerto Campanario, por compras según escrituras públicas a los cuatro herederos de su dueño Salvador de Aparicio:

“... con partes entre otros interesados en ella... por cuya razón están indivisas... con posesión inmemorial... y para que esta posesión tan arraigada no se altere ni innove y se originen pleitos... se ha de servir V. Merced se dé posesión de lo que me corresponde, se me manifieste y enseñe por personas intelegibles para evitar pleitos, a fin de que no se perturben ni inquieten con el tiempo, así a mi como a los sitios y cultivos que han poseído los indios del servicio". (Doc. Borda).

En esta solicitud puede conocerse la posesión que los dueños de fuera tenían frente a los isleños residentes en sus propiedades. Se les reconocía el derecho a tener su casa y sitios de cultivo, pero no se pensaba que eso fuera de ellos, sino sólo como algo en préstamo. Los indígenas que tenían sus viviendas o parcelas pequeñas de cultivo, dentro de lo que era su hacienda eran sus colonos, y tenían la obligación de servirles y hacer trabajos personales, no sólo en la isla sino fuera de ella, donde estuvieren los dueños, así muchos taquileños fueron a Acora, Taraco, Ilave. Este era el anhelo que animaba a muchos dueños. Por el hecho de tener su vivienda o pedazos de tierras para cultivar en sus propiedades, los indígenas tenían la obligación de trabajar para ellos otorgándoles con este acto un estatus de prestigio, de hacendados puneños. En general, este es el patrón que norma el funcionamiento de muchas haciendas peruanas: continuar con viejas pautas establecidas. El conflicto surge cuando la relación de los dueños con los indígenas se mantiene en un plano de abuso y no de convivencia.

El 19 de abril de 1757 Antonio Espinoza de los Monteros es comisionado para que notifique a los interesados en las islas a fin de que no perturben a la nueva dueña bajo ningún pretexto "ni motivo, como asimismo dejen quietos en sus lugares a los indios del servicio de esta parte y sus pertenencias..." (Doc. Borda).

El 27 de abril llega el Comisionado a Capachica y notifica la orden anterior en presencia de los dueños interesados Estefanía y Josefa Aparicio, Asencia y Felipe Escarcena, y Felipe Camino. Cinco usufructuarios de las islas.

El 30 de abril en la isla Amantani Antonio de Espinoza da posesión de la isla a Silvestre de los Cuentas que representaba a su mujer María Rosa Bravo de Núñez. He aquí lo que dice el documento Borda sobre esta posesión:

“...el comisionado lo cogió de la mano (a Silvestre Cuentas) en nombre de su esposa y le dio posesión de los pagos, chacras, cultivos, corrales, cerros, aguadas, quebradas y casas que tuviera y poseyeran Salvador de Aparicio y sus herederos ... El pago, tablones y cultivos de Capellani, Utargata, Pasallani, Toribelén, Yacastique, Cconoscay, Tacacachi, Urinuconi, Caragachi, Cuchilluni y sus corrales que están en el pueblo de los gentiles con el tendal y corral de chuños, lo aprendió real corporal Juri Domini Velquasi sin contradicción de persona alguna, quieta y pacíficamente y en seña de ella en cada un pago de chacras, corrales, cultivos y quebradas según y como poseyeron y tuvieron sus pasados, se paseó, revolcó, arrancó yerba y tiró piedras en nombre de la dicha señora su esposa, gritando en alta voz: Posesión, Posesión ...".

Es así como la familia Cuentas se convierte en propietaria de las dos islas y del puerto de Campanario en Capachica. 
En 1762 Silvestre Cuentas realiza obras portuarias en la isla de Amantani y en Chullumi, península de Capachica (Doc. Cáceres Olazo).

El 23 de diciembre de 1774, en la ciudad de Huancané, el bachiller Blas de Rojo, del Obispado de la Paz, vende las tierras que poseía en las islas y que heredó de su padre Miguel Rojo que estuvo casado con Anastasia de Aparicio ya difuntos (según testamento de Miguel Rojo hecho en 1737) a María Rosa Bravo de los Cuentas, en la suma de 1000 pesos. En la escritura de venta manifiesta que cobró 2184 pesos a la señora Bravo, él y su hermano, y que "estimulado, por su conciencia, le pide le perdone la demasía. ... y en pago por no tener solvencia le da a cambio la posesión que tiene en las islas Amantani y Taquile, apartándose para siempre de esas propiedades ... y que esto es la única escritura de venta sobre esas tierras" (Doc. Borda).

Esto hace suponer la serie de pleitos y dificultades que tuvo la señora Bravo de los Cuentas con los otros herederos de las islas. Miguel Rojo tuvo cuatro hijos: el bachiller Blas, Francisco, María y Leocadia. Blas declara ser el único heredero de su padre por muerte de sus hermanos Francisco y María, pero no dice nada de su hermana Leocadia que más adelante aparecerá. La herencia de los Rojo viene del lado de su madre Anastasia, que pudo haber sido hija de Joseph de Aparicio (hermano de Salvador) o, lo más probable, heredera de Francisco o Joseph, hermanos de Juan Aparicio.

Un año después, el 23 de enero de 1775, en la ciudad de Puno, Antonia de Aparicio, vecina de Capachica e hija legítima de Joseph de Aparicio, hermano de Salvador, vende su acción a María Rosa Bravo de los Cuentas en 250 pesos. Lo hace en nombre de sus herederos y sucesores.

El 26 de junio Agustín Herrera "marido que fue de Leocadia Rojo", hija legítima de Miguel Rojo y Anastasia de Aparicio, pide vender la herencia de sus dos hijos vivos Simón Tadeo y Ursula Herrera Rojo, a la señora Bravo. Leocadia murió en 1755 y tuvo cuatro hijos: Andrés y Juana (muertos antes de 1775) y Ursula y Simón Tadeo. El 28 de junio se firma la escritura de venta de la herencia de estos dos hermanos a favor de la señora Bravo de los Cuentas en la suma de 300 pesos. En la escritura manifiestan los vendedores que hace 16 años (1759) su padre hizo escritura de arriendo de sus propiedades en Amantani y Taquile en favor de Tomás Carrión por el período de siete años, quien se aprovechó sin pagarles cosa alguna. En esta venta se incluyó la parte de sus hermanos muertos y que heredó su padre Agustín Herrera. La persona que informó favorablemente sobre la procedencia de esta venta fue el general Miguel Antonio de San Román, que era Corregidor y Justicia Mayor de Su Majestad.

El 12 de junio de 1776 Juan Escarsena, residente en el pueblo de San Salvador de Capachica, vende la parte que posee en las islas y puerto Campanario a María Rosa Bravo de los Cuentas en la suma de 145 pesos. Este era hijo de Ignacia Aparicio y declara que su herencia, por justo título, le viene de sus antepasados (Doc. Borda).

El 23 de octubre de 1779 en la ciudad de Puno, Josefa Aparicio, vecina de la provincia de Lampa vende igualmente la parte que por herencia de sus padres posee en "las islas Amantani y Taquili” y en puerto Campanario a la señora María Rosa Bravo de los Cuentas en la suma de 500 pesos corrientes. El que firma la escritura es su hijo Fernando Aedo. Es probable que sea hermana de Antonia de Aparicio y ambas hijas de Joseph, hermano de Salvador de Aparicio.

En septiembre de 1786 María Rosa Bravo de Núñez presenta un "pedimento" en el cual declara que es viuda de Silvestre de los Cuentas y pide que se cite a cuantos interesados hubiera o se crean con derecho a las tierras que posee en las islas Amantani, Taquile y en puerto Campanario, las cuales compró "según los documentos que acompaña con 
toda la solemnidad necesaria" a Josefa de Aparicio, Antonia Aparicio, Juan Escarsena, Agustín Herrera y el bachiller Blas Rojo por sí y por Francisco y María sus hermanos, todos herederos universales pro-indivisos en su respectiva línea de Francisco, José y Juan Aparicio, dueños y poseedores que fueron con justo y legítimo título de dichas propiedades ...

"La citación que pide era para que se le de judicialmente su verdadera posesión ... para que en virtud de su autoridad, decreto judicial, amparo y defensa superior, que desde luego imploro, se corten de raíz aquellas inquietudes que por introducciones violentas de otros individuos extraños se me infieren...".

El cuatro de septiembre de 1786, vista esta petición, se ordena se dé la posesión solicitada, comisionándose para ello a Tomás Fernández. El ocho de septiembre el comisionado comunica a la interesada que nombre su apoderado para que vaya a las islas a efectuar la posesión, notificándose a los demás interesados esa disposición y que con plenos poderes de la señora María Rosa Bravo de los Cuentas se vaya a las islas para el dicho reconocimiento. El 10 de septiembre el comisionado citó desde Capachica a Sabina Almeida, Javier Flores y Francisco Acuña, circunvecinos a las propiedades de la señora Bravo de los Cuentas, quienes no tuvieron nada que pedir. Tomás Melgar hizo oposición por parte de María Rojo. Gregorio Rojo dijo ser hijo natural de Francisco Rojo por cuya parte se oponía. Lucas Herrera se oponía por parte de Josefa Aparicio y María Ramos por su difunto marido Juan Escarsena. El Comisionado ordenó a todos estos opositores que comparecieran ante el Teniente de Gobernación, Intendente en la ciudad de Puno, demandando o formalizando el derecho que pudieran tener; el plazo para hacerlo sería de 15 días después de cuyo término sería nula su contradicción. El 13 de septiembre de 1786 en Puno, igualmente, presenta oposición Hilario Gallegos, marido de Bernardina Pacheco, por parte de Antonia Aparicio (Doc. Borda).

En estas circunstancias, muere la señora María Rosa Bravo de Núñez viuda de los Cuentas. Hasta esa fecha ella fue la que más tenaz y tesoneramente logró comprar la mayor cantidad de tierras en las dos islas. Su paciencia y perseverancia hicieron posible crear lo que sería más tarde la gran heredad de la familia Cuentas.

Hasta esa fecha el proceso de la propiedad está estrechamente unido a las dos islas y con marcada importancia para Amantani por su extensión y productividad. Taquile no ofrecía gran interés, no hay noticia de visitas a ella, ni de nada especial, solamente aparece mencionada debido a que la familia Cuentas toma mayor interés en ella que en Amantani, en la cual los conflictos comenzaban a ser serios.

La primera noticia concreta sobre tierras que hemos encontrado acerca de Taquile aparece en 1791 (Doc. Borda). A la muerte de María Rosa Bravo de Núñez, sus hijos legítimos Andrés, abogado de las Reales Audiencias de Charcas y el Cusco, y Manuel Antonio, ambos naturales de Puno, herederos y albaceas y como tal poseedores de los bienes de su difunta madre, solicitaron que se les dé posesión en las islas y el puerto que no pudieron dar a su madre porque los oponentes no se presentaron en el plazo de 15 días que se fijó.

El ocho de agosto de 1791, en la ciudad de Chucuito, ante esta petición se ordena su respectivo cumplimiento, comisionándose para ello a Martín Terrova, el cual el 16 de agosto hace las notificaciones a las partes interesadas en la ciudad de Puno. El 20 de agosto Tadeo Espinoza, apoderado de los hermanos Cuentas, recibe la posesión de sus derechos en esa isla, para lo cual realizan igual procedimiento que el hecho cuando recibió esas propiedades Silvestre de los Cuentas en 1757. En esa misma fecha se notificó en Taquile y Campanario la orden de posesión hecha en Amantani. Hasta el 25 de agosto continuó realizándose la 
posesión en Amantani. El 29 fue la del puerto Campanario y el primero de septiembre la de Taquile, en la que recorrieron el primer día los siguientes lugares: Saramuri, Collino Chico, Atún Collino, Patahuasi, Cruz Pata, Guaillano, Pogmgno, Cangallo, Chujuno, Cóndor puñuna cucho, Inca cancha, Guichai, Collata, Taguichuño, Igleciano, Chuño pampa, Uchuy Chilcano, Atún Chilcano, Queguigaco y Uchuy Carillano. A excepción de Guichai y Queguigaco todos esos lugares conservan actualmente los nombres mencionados. El segundo día o sea el dos de septiembre, recorrieron los siguientes lugares dando posesión: Matansano, Siguircano, Estancia, Mategno, Alisuno, Lacayano, Sayguano, Cantutano, Sancalaguano, Chuño Pata, Atún Carilano y Ejejeno, igualmente, lugares que hasta hoy se conoce con esos nombres, a excepción de Siguircano. La visita del primer día correspondió a los suyo Chuñopampa y Chilkano. La del segundo día, a los suyu Estancia y Chilcano. Consultando los mapas que consignamos en este estudio, fácilmente pueden seguirse el rumbo tomado y ubicar las posesiones (Doc. Borda).

\section{Fines del siglo XVIII y siglo XIX}

Hemos descrito como en el siglo XVI la isla perteneció a un dueño: Pedro González. En el siglo XVII a Pedro Pacheco de Chávez y Andrés Aparicio. En el siglo XVIII a la familia Aparicio durante su primera mitad, después se produjo un gran fraccionamiento debido a problemas de herencia, hasta que al finalizar el siglo la señora María Rosa Bravo de Núñez de los Cuentas vuelve a concentrar en una sola persona la propiedad. En siglo XIX ocurrirá un nuevo fraccionamiento al pasar la propiedad a poder de los herederos de la familia Cuentas. Analicemos cómo se realiza ese fraccionamiento.

Ha sido posible reconstruir en gran parte la historia de la propiedad en Taquile gracias a la valiosa información personal que nos proporcionó el doctor Enrique Cuentas, uno de los dueños, y al trabajo preparado por el señor J. Alberto Cuentas, otro de los dueños. Igualmente, han contribuido con sus valiosos informes la señora Antonina Cuentas y el señor Martín Fernández, herederos de la familia Cuentas y residentes en la isla, así como también los líderes isleños Prudencio y Lino Huata.

La señora María Rosa Fernanda Bravo de Núñez que fue dueña de Taquile desde 1757 a 1788 (?) tuvo por padre a Juan Antonio Bravo de Saravia, un español radicado en Puno, azoguero y dueño de minas y socavones reales en ese departamento, y estuvo casada con Silvestre de los Cuentas y Valdez, quien pertenecía a una antigua familia de Toledo (España). Su primer antepasado del que se tiene noticias es Pedro González de los Cuentas, Escribano Mayor del Ayuntamiento de Toledo, que tuvo un hijo llamado Fernán Pérez de los Cuentas y Caya, Contador de Juan II. El heredero de éste, Pedro González de los Cuentas y Caya, también nacido en Toledo en 1540, fue el primero de la familia que vino al Perú, avecindándose en Lima donde se casó el 27 de enero de 1570 con Bernarda Niño de Guzmán y Valverde, de la que tuvo ocho hijos. Uno de ellos, Antonio Pérez de los Cuentas Niño de Guzmán se casó con Eugenia Estacio Conde en la ciudad de la Paz en 1620, de cuyo matrimonio tuvieron cinco hijos. El menor Josef de los Cuentas Estacio, también nacido en La Paz, en 1640 se casó con María Blasa Valdez y tuvieron dos hijos Silvestre e Ignacia. Silvestre de los Cuentas y Valdez nació en Puno el 31 de diciembre de 1705 y murió el 27 de octubre de 1765. Estuvo casado en primeras nupcias con Manuela Velarde y en segundas nupcias con María Rosa Fernanda Bravo de Núñez, matrimonio celebrado en Puno en 1744. De su primer matrimonio tuvo dos hijos y del segundo nueve, los cuales van a ser los herederos de sus propiedades en Taquile y Amantani. Ellos fueron:

1 Pedro Antonio de los Cuentas y Bravo (nacido en 1748).

2. Gregoria María Antonia (1748). 
3. Andrés (1750).

4. Francisca (1752).

5. Josefa (1755).

6. Gregoria (1757).

7. Manuel Antonio (1759).

8. Juan Valentín (1760).

9. Juan Emeterio (1762).

Los Cuentas estuvieron emparentados con el primer Obispo del Perú Fray Vicente Valverde y Niño de Guzmán, por lo cual tuvieron una Real Cédula de siete de noviembre de 1564 que los favorecía y en virtud de ella no podían ser juzgados por tribunales americanos sin antes serlo por españoles. En tres oportunidades sus herederos esgrimieron este favor: en 1707 Juan de los Cuentas Estacio a la edad de 69 años en La Paz; en 1710 Juan Francisco de los Cuentas Arbilo y Berris en Lima a la edad de 82 años y, por último, en 1814, Miguel Pascual San Román, el cual actuó en las filas de Pumacahua y fue tomado preso en Puno, permaneciendo en su casa dos años hasta que España resolviese lo que debería hacerse debido a que esgrimió esta Real Cédula de los Cuentas, de cuya familia él era miembro; pero en 1816 cuando el Virrey Pezuela pasó por Puno, sin esperar respuesta, lo hizo fusilar.

En el expediente Borda se menciona como segundo apellido de Silvestre el de Niño Guzmán.

En 1791, a la muerte de María Rosa Bravo de Núñez viuda de los Cuentas, sus hijos Andrés y Manuel Antonio, en representación del resto de los herederos, recibieron la posesión de sus propiedades en las islas. Andrés, abogado, fue catedrático de Artes en la Real Universidad de San Antonio de Abad del Cusco y no tuvo descendencia. El otro hermano, Manuel Antonio, casado dos veces, tuvo un hijo de su primer matrimonio llamado Pedro Nolasco, nacido en 1779. Manuel Antonio murió en Puno en 1799. Francisca, Juan Valentín y Josefa, los otros hermanos, no tuvieron descendencia. Estos cinco hijos de Silvestre Cuentas perdieron la herencia, quedando ella para los otros cuatro:

- Pedro Antonio, el mayor de todos, tuvo tres hijos: Eugenia, Antonia, Sebastiana y Leandro (el mayor nacido en 1780).

- Gregoria María Antonia murió en la isla Amantani, dejando cuatro hijos: Miguel 1, María Eulalia, Miguel II y Tomás Risco de los Cuentas.

- Gregoria, casada con Miguel Antonio de San Román, tuvo como heredero a su hijo Miguel Pascual San Román de los Cuentas, nacido en Puno en 1778. De su segundo matrimonio tuvo otro hijo, José Benito Carrasco de los Cuentas que nació en 1786, el cual parece que no participó de la herencia en las islas.

- Juan Emeterio, el menor de todos, fue casado dos veces. De su primer matrimonio tuvo dos hijos Manuel y María Antonia de los Cuentas Gallegos y del segundo Mariano, Juan Manuel Agustín Antonio, María Juana, María Magdalena, Ana y Manuela.

De estos cuatro herederos de la familia Cuentas, la gran propiedad se concentra en Juan Emeterio de los Cuentas y Bravo, el hijo menor, y una parte en Gregoria la que se casó con Miguel Antonio de San Román y que por venta pasó su propiedad a poder de la familia Borda.

Más adelante veremos cómo fue el origen de la propiedad de los Borda en Taquile.

Sigamos con la herencia de los Cuentas a través de Juan Emeterio, quien probablemente compró las acciones de sus otros hermanos Pedro Antonio y Gregoria María Antonia.

Seis de los hijos de Juan Emeterio de los Cuentas y Bravo fueron sus herederos, así lo declara Natalia Herrera viuda de Alvarez en la escritura de venta que hizo a favor del 
doctor Jacinto Zúñiga Béjar en 1917. Los otros hijos, Ana y Manuela de los Cuentas Cáceres y Manuel de los Cuentas Gallegos, perdieron la herencia, no sabemos cómo. Los que heredaron fueron los siguientes:

- Juan Manuel de los Cuentas y Cáceres que tuvo cuatro hijos: Manuel, Alejandro, Juan Crisóstomo, Juana y Romualda Cuentas y Borda.

- Agustín Antonio de los Cuentas y Cáceres que tuvo tres hijos: Néstor, Manuela y Ana.

- María Juana de los Cuentas y Cáceres que tuvo dos hijas: Manuela e Ignacio Romero de los Cuentas.

- María Magdalena de los Cuentas y Cáceres, sin descendencia.

- Mariano de los Cuentas y Cáceres que se casó con Felipa Aparicio en 1868, parece que no dejó descendencia; y

- María Antonio de los Cuentas y Gallego nacida en 1795, sin descendencia.

La propiedad de Taquile y Amantani en la primera mitad del siglo XIX correspondía a estos seis herederos y a la tía Gregoria de los Cuentas y Bravo.

Tres de estos seis hijos, herederos de Juan Emeterio, perdieron sus derechos, María Magdalena por venta que hizo de sus acciones a su sobrino Néstor en 1892. De los otros dos hermanos Mariano y María Antonia no hay información de cómo los perdieron. De esta manera, la propiedad queda en manos de los hermanos Juan Manuel, Agustín y María Juana.

Veamos cómo continúa la heredad de los Cuentas a través de estos tres hermanos:

1. Juan Manuel de los Cuentas y Cáceres. Dicen los informantes que jugando pinta una noche perdió una parte de su propiedad en Taquile y que el favorecido fue un tal Núñez. En un documento de matrículas de contribuyentes de 1830, existente en el Archivo Histórico del Ministerio de Hacienda (N. $\left.{ }^{\circ} 122\right)$, aparece Mariano Núñez como dueño de la isla Taquile. Probablemente fue uno de los tantos encargados que tenían los Cuentas en la isla pues, generalmente, ellos tenían un indígena como kipu e iban sólo para la siembra y cosecha, encargando el cuidado unas veces a un mestizo de Puno o algún miembro de la familia que lo deseare. El temor a la lejanía y aislamiento era motivo de este procedimiento. Según una versión no es posible que el ganador en el juego haya sido Mariano Núñez porque el 23 de noviembre de 1830 la viuda de Juan Emeterio de los Cuentas y Bravo pidió en Puno una copia de los títulos de propiedad por "albacea de sus menores hijos" y si la información es correcta Juan Manuel debió haber sido muy niño en 1830. Entonces, puede ser cierta la posibilidad de que sea el mismo Juan Emeterio el que perdiera en el juego y si es así Mariano Núñez pudo ser el afortunado y poseedor de propiedades en Taquile en 1830 y como tal declaró al hacerse la matrícula de contribuyentes de ese año.

El hecho es que a partir de 1830 aparecen los Núñez como dueños en Taquile, ellos darán origen a la propiedad de los Galindo y los Flores años más tarde, como veremos más adelante.

Juan Manuel de los Cuentas Cáceres tuvo cuatro hijos:

a. Manuel Alejandro Cuentas y Borda, que se casó con Francisca Martínez en 1863 en la ciudad de Puno, con la cual tuvo cuatro hijos: Prudencio, Juana, Norberta y Toribia de los Cuentas Martínez. En segundo matrimonio con María Monje con quien tuvo, asimismo dos hijos. Antonina y Alejandro Ricardo. Esta es la línea más importante de la herencia de los Cuentas en relación a Taquile. La señora Antonina Cuentas Monje vive actualmente en la isla ratificando con su presencia la heredad de los Cuentas. Prudencio, el mayor de todos, hizo un arreglo con sus hermanos y quedó dueño absoluto de sus acciones en Amantani, pero conservando su parte en Taquile. Así, la herencia de las dos islas para los Cuentas comienza a separarse. 
Igual va a suceder con los otros hermanos de Manuel Alejandro.

De estos seis herederos de Manuel Alejandro Cuentas y Borda:

- La señora Antonina Cuentas Monje administra personalmente sus acciones, así como las de Norberta su hermana, cuya heredera es su hija Natividad que vive en Taraco. La de su hermano Prudencio cuyos herederos son sus hijos Daniel, que también vive en Taraco, y Julio en Lima. Y conserva las acciones de sus hermanas ya difuntas, Juana que murió sin dejar hijos y Toribia que tiene tres hijos radicados ahora en Moquegua.

- Las acciones de Alejandro Ricardo Cuentas Monje las administra su viuda la señora Hortencia Ormachea viuda de Cuentas, la cual tiene un kipu en Taquile. Sus herederos son sus dos hijos Enrique y Jorge. Esta rama de Manuel Alejandro Cuentas y Borda está indivisa, se mantiene íntegra debido solamente al empeño de la señora Antonina Cuentas Monje.

b. Juan Crisóstomo Cuentas y Borda tuvo cinco hijos: Julia, Magdalena, José Luis, Manuela y María. Vendió una parte de su herencia a su tío Néstor Cuentas, la otra parte la heredaron estos cinco hijos. Magdalena que vivió mucho tiempo en Taquile reunió y poseyó toda la heredad, dejando a su muerte la propiedad a su hijo Martín Fernández, quien también vive actualmente en Taquile manteniendo sus derechos con su presencia permanente en la isla.

c. Juana Cuentas Borda, sin datos. Parece que no dejó herederos.

d. Romualda Cuentas Borda, igualmente sin herederos.

2. Agustín Antonio de los Cuentas y Cáceres, el otro hermano de Juan Manuel de los Cuentas y Cáceres tuvo tres hijos: Néstor, Manuela y Ana. Compró de su hermana María Magdalena una parte de su herencia que agregó a sus bienes. El 13 de marzo de 1851, por testamento público, pasó la herencia a sus hijos. Néstor lo administró y en 1892 adquirió la parte que le quedaba a su tía María Magdalena Cuentas y Cáceres y otra parte a su otro tío Juan Crisóstomo Cuentas y Borda. Por último, el 19 de agosto de 1911, mediante una transacción, añadió a sus bienes la parte de sus hermanas Manuela y Ana.

Néstor Cuentas tuvo tres hijos, Sofía, Filomena y Juan de Dios, los cuales fueron los herederos de esta otra gran parte de la heredad de los Cuentas, de acuerdo al testamento hecho por su padre el 12 de julio de 1913. El 20 de octubre de 1916, los tres hermanos venden en la suma de 1000 soles todos sus derechos en Taquile al doctor Jacinto Zúñiga Béjar. Compra muy importante porque como veremos más adelante esta propiedad pasara a los taquileños por venta que les hizo el doctor Zúñiga Béjar en 1942 dando inicio a la compra de tierras de los indígenas con escritura pública.

3. María Juana de los Cuentas y Cáceres tuvo dos hijas Manuela e Ignacia Romero de los Cuentas. Manuela, casada con Pedro Llanos, tuvo una hija, Carmen Llanos Romero quien a su vez tuvo por hija a Natalia Herrera Llanos. Esta señora, la bisnieta, es la que se convirtió en heredera por esta línea de todas las acciones de María Juana de los Cuentas y Cáceres y de una parte que esta señora compró a su hermana María Magdalena. La confirmación de esta herencia fue hecha por escritura de venta y adjudicación de fecha 25 de junio de 1895 realizada por María Juana de los Cuentas y Cáceres viuda de Bustamante a su favor. La herencia correspondía a las islas Taquile y Amantani. No tenemos datos sobre la herencia de la otra hija Ignacia Romero de los Cuentas.

Lo interesante en este proceso de la propiedad en la isla Taquile es que el 30 de octubre de 1917 esta señora Natalia Herrera Llanos viuda de Álvarez vende todos sus derechos de propiedad en la isla Taquile al doctor Jacinto Zúñiga Béjar en la suma de 500 soles, propiedad que años más tarde pasará también a poder de los taquileños vendida con escritura pública. 


\section{Siglo XX}

En la segunda mitad del siglo XIX son dueños de Taquile los tres hijos de Juan Emeterio de los Cuentas y Bravo, los San Román que continúan con la herencia de Gregorio de los Cuentas y Bravo y los Núñez que dieron origen a la propiedad de los Galindo y los Flores.

La heredad de uno de los tres hijos de Juan Emeterio o sea de Juan Manuel Cuentas y Cáceres está todavía indivisa y es la que continúa desde 1757 hasta el presente de la herencia de los Cuentas. Los dos dueños que actualmente viven en Taquile pertenecen a esta rama. Tal vez el hecho de que esté indivisa ha sido una defensa contra su desaparición, porque los derechos de los otros dos hermanos que estaban correctos pasaron por intermedio del doctor Zúñiga Bejar a los taquileños mediante escrituras públicas de venta. Es así como en el presente siglo los Cuentas mantienen solamente una pequeña propiedad en Taquile. Para una isla que apenas tiene casi $4 \mathrm{~km}$ de largo por $2 \mathrm{~km}$ de ancho o sea $7.54 \mathrm{~km}^{2}$, cuya parte utilizable sólo alcanza la tercera parte, el excesivo fraccionamiento y su usufructo por muchos dueños de fuera (hacendados) y los isleños que suman ahora 640 habitantes (en el año 1830 eran 240), apenas puede producir lo necesario para el sustento de su población y para los dueños de fuera cuando más para unos pocos meses.

Actualmente los dos dueños, que viven en la isla se aferran a la tradicional heredad de los Cuentas, aún a costa de grandes sacrificios, pero esta vez lo hacen movidos por la necesidad, solamente les queda esa propiedad, en ningún otro sitio tienen tierras, son pobres. Viven en la isla en igual forma que los isleños, gozando únicamente del estatus de propietarios, lo que les resulta mejor que vivir en la ciudad donde su existencia sería precaria.

Queda solamente por examinar los orígenes de la propiedad de las familias San RománBorda, Núñez-Galindo-Flores y del doctor Jacinto Zúñiga Bejar.

1. San Román-Borda. Su origen es el más antiguo. Viene de la rama de Gregorio de los Cuentas y Bravo, hija de Silvestre Cuentas, nacida en 1757 y casada en primeras nupcias con Miguel Antonio San Román del cual tuvo un hijo llamado Miguel Pascual San Román de los Cuentas que nació en Puno en 1778. Desde esa fecha data la herencia de los San Román en Taquile y Amantani.

El padre de Miguel Antonio San Román fue un minero asturiano llamado Miguel Pascual San Román ${ }^{2}$. Este Miguel Pascual San Román de los Cuentas fue uno de los que tuvo que utilizar la Real Cédula a favor de los Cuentas por ser descendiente del Obispo Vicente Valverde, a pesar de lo cual fue fusilado en 1816 por haber participado en la rebelión de Pumacahua. Estuvo casado con María Meza en primeras nupcias, uno de cuyos hijos fue Miguel Antonio quien llegó a ser Presidente de la República y Gran Mariscal del Perú, nacido en Puno el 17 de marzo de 1802 y continuador de la herencia de los Cuentas en Taquile y Amantani.

El 15 de noviembre de 1890 en la ciudad de Arequipa se llevó a cabo la partición de los bienes del Mariscal San Román entre sus hijos los Coroneles Miguel y Manuel y entre las muchas pertenencias que declara y aparecen en el testimonio que posee la familia Borda de Puno, como cláusula N. ${ }^{\circ} 12$ se menciona:

"Bienes partibles entre ambos hermanos (por parte de padre): una casa en Arequipa, calle Cordova No. 3, dos casas en Puno en la calle Comercio, unos terrenos situados en la isla de Amantani y Taquile que le hemos puesto el precio convencional de S/. $4,000.00 "$.

Más adelante en la parte de adjudicaciones y pago se dice:

2 Ver Romero, Emilio. Monografía de Puno, p. 41 y Mendiburu, Manuel de Diccionario biográfico tomo X, p. 55. 
"Hijuela del Coronel Miguel San Román la mitad de los terrenos en las islas Amantani y Taquile S/. 2,000.00. Hijuela del Coronel Manuel San Román, la mitad de los terrenos de las islas Amantaní y Taquile. S/. 2,000.00".

La escritura de esta repartición fue el 24 de marzo de 1897 en la ciudad de Arequipa. En esos documentos hay datos interesantes sobre la vida del Mariscal, cuya mujer fue Josefa de Oviedos.

En 1900 (?) Máximo Borda compró a los hermanos San Román sus propiedades en las dos islas. Por esta rama el actual heredero es el señor Belisario Borda, dentista, quien regaló su propiedad en Taquile a su yerno Julio Solís, cuando se casó con su hija.

El señor Solís es otro de los actuales dueños en la isla y su propiedad está al cuidado de un kipu taquileño.Un grupo de isleños encabezados por Juan de Dios Cruz está reuniendo dinero con la finalidad de adquirir esta propiedad.

2. Núñez-Galindo-Flores. La propiedad de estas familias proviene de 1820 a 1830 , sin existir una referencia concreta. Parece que Juan Manuel de los Cuentas y Cáceres o su padre Juan Emeterio fueron los que le dieron origen. Una noche "jugando pinta" ganó Mariano Núñez una acción de la herencia de los Cuentas en Taquile, como ya se mencionó. Ya hemos indicado como aparece en 1830 Mariano Núñez como dueño en Taquile, según el documento del Archivo Histórico del Ministerio de Hacienda. La propiedad pasó, por herencia o venta, a poder de Benjamín Flores, el cual estuvo casado con Andrea Galindo. Pedro Galindo, tío de ésta, compró una parte de la herencia, la otra parte continuó en poder de los Flores, hasta hace pocos años en que la abandonaron, usufructuándola los isleños. Prudencio Huata, uno de éstos, tuvo un juicio con los herederos pidiendo la exhibición de títulos, debido a que uno de ellos, Faustino Flores, quiso reclamarla. Los Flores perdieron el juicio y Prudencio pasó a ocupar esta propiedad que comprendía una sección en los suyu Chuñopampa y Kollino Grande y en Koano Pata, Alisuno Chico y Alisuno. Hasta esa fecha, 1947, los Flores tenían un kipu taquileño.

Los Galindo dejaron sus pertenencias a los Flores.

3. Jacinto Zúñiga Bejar. Dos de los herederos de Juan Manuel Cuentas y Cáceres, Agustín y María Juana, por intermedio de sus herederos dieron origen a la propiedad de tierras en Taquile que el doctor Zúñiga Béjar compró en 1916 a los hermanos Juan de Dios, Sofía y Filomena de los Cuentas y en 1917 a Natalia Herrera viuda de Álvarez. El doctor Jacinto Zúñiga Béjar era Vocal de la Corte Superior de Puno y allí seguramente fue testigo excepcional de todas las desventuras de la población indígena en el altiplano y cuando se le presentó la ocasión de ayudarlos lo hizo inmediatamente. En 1937 les vendió a un grupo de isleños, encabezados por Prudencio Huata, en la suma de 1,500.00 soles sus derechos de propiedad en la isla, aunque también a esta venta influyó la tenacidad y voluntad de Prudencio Huata. Al examinar cómo fue esta adquisición de los isleños detallaremos sus pormenores. Pero lo importante es destacar lo que significó la emoción social del doctor Zúñiga Bejar en el proceso de la lucha de los taquileños por lograr la propiedad de sus tierras. 


\section{Situación actual de la propiedad en la isla (1957)}

Como conclusión podemos resumir la situación actual de la propiedad en Taquile.

1957. Propiedad en poder de dueños de fuera:

\section{Herencia de los Cuentas:}

a. La mayor parte la administra personalmente la señora Antonina Cuentas viuda de Ponce de más de 70 años. Corresponde a los derechos de su padre Manuel Alejandro Cuentas y Borda. Bajo su cuidado están los derechos de sus hermanos Norberta, Toribia, Juana y Prudencio (todos difuntos).

b. Otra parte está bajo el cuidado de la señora Hortensia Ormachea viuda de Cuentas, heredera de los derechos de su esposo Alejandro Ricardo Cuentas. La administración en la isla está a cargo de un kipu. Alejandro Ricardo Cuentas fue hermano de la señora Antonina Cuentas viuda de Ponce.

c. Del otro hermano de Manuel Alejandro Cuentas y Borda, llamado Juan Crisóstomo proviene la propiedad de Martín Fernández, sexagenario, que también vive en la isla administrando sus tierras.

Toda esta heredad de los Cuentas está indivisa.

\section{Herencia de los Borda:}

En poder de Julio Solís que tiene como administrador un kipu.

Hasta aquí la historia de la actual propiedad de los dueños mestizos, ahora pasemos a describir la situación de los indígenas.

\section{Propiedad en poder de los taquileños}

Al llevarse a cabo el primer remate de Taquile en el siglo XVI, terminó para el isleño un tradicional sistema de economía y con él toda una forma de vida. Ya no habría más una organización comunal, había aparecido un nuevo y gran dueño que les exigía trabajo y lo más sorprendente era que ya no les repartía sus frutos sino que se los llevaba. La isla perfectamente distribuida en dos ayllu, con una organización bien coordinada de trabajo, que había creado un sobresaliente sistema de rotación de cultivos y de trabajos hidráulicos, tales como el aprovechamiento de las pendientes tan rocosas de la isla rodeándolas de impresionantes andenerías en toda su extensión, con una estructura económica basada en la explotación racional de la tierra al máximo lo que les permitía vivir plenamente de ella, había pleno empleo y alimentación para todos, además de vivienda, vestido y hasta poder almacenar víveres -lo demuestran los restos antiguos de Janaj Care y Uray Care- y contribuir con parte de sus mejores frutos al Estado Inca ${ }^{3}$; enfrentaba un nuevo sistema en el cual ya no habría de vivir en forma similar a lo existente, ni desarrollar técnicas para el trabajo de la tierra y ni siquiera tener la capacidad de reconstruir andenes, antigua habilidad tecnológica agraria que iría desapareciendo en el nuevo isleño, hasta el extremo de llegar en muchas oportunidades a olvidar por completo conocimientos y no poder recrear su exitosa tecnología adaptada a su realidad. No habría más estimulo y ejemplo a seguir, no habría una estructuración social-política-económica y mágico religiosa que le brindara bienestar y le permitiera contribuir a desarrollar mejores niveles de vida, no habría más un sistema educativo socializante que lo acompañara durante todo su ciclo de vida, solamente quedaba seguir la nueva rutina lo más cautelosa y acertadamente posible para sobrevivir.

Los últimos años del siglo XVI le hicieron constatar en toda su crudeza este cambio que él creyó momentáneo. Desde 1533 se rompió su conexión con el Imperio Inca hasta 1580 en

3 Taquile y Amantani fueron famosos en el Imperio Inca por su producción de papas, al extremo de ser consideradas como semilleras. 
que por primera vez se enfrenta a algo nuevo: el mundo que representaba Pedro González, primer feudatario y "hacendado", aunque este primer contacto fuera fugaz y débil, fue el comienzo de la nueva realidad, la dependencia, todos debían trabajar para él y nada de las tierras de la isla era más de ellos sino del recién llegado español. Su presencia no duró mucho porque al finalizar el siglo desaparece y Taquile queda abandonada, continuando con su ritmo de autonomía, pero en espera y zozobra.

La isla permanece aislada hasta 1644 en que nuevamente ve aparecer otro propietario. Este hecho tiene que entenderse como algo relativo porque ya los misioneros católicos ejercían un pequeño control, les hicieron construir una iglesia y con ella aprendieron una concepción religiosa también diferente. En estos dos períodos de autonomía, más de ocho décadas, su conexión con Amantani y Capachica debió continuar, estos tres lugares eran una área de interrelación propia, y fue un momento en el cual cuantos encuentros habrían sucedido, cuitas, miedos, temores, remotas esperanzas, que contribuyeron en mucho a explicar y entender lo que para el taquileño significó el encuentro, que no fue tan brutal y demoledor como en otras regiones del país, aunado a su ubicación una islita, su poca población, su lejanía y lo peligroso que era llegar a ella. Más tarde mucho de este espíritu conservador y tesonero del isleño taquileño tuvo su expresión de reivindicación en las cuatro primeras décadas del siglo XX cuando decidió y luchó por tener la propiedad de sus tierras con títulos propios siguiendo el orden establecido por el Perú oficial.

Desde 1644 hasta la década de 1920 en que surge el deseo de recuperar su propiedad, la nueva forma de vida se desarrolló míseramente para el isleño, con un nivel casi infrahumano, las pestes, los viajes a otros lugares en sus servicios personales y la contemplación de prisioneros políticos acompañó este cuadro sombrío. En plena época de dominación española, durante el período de la independencia y dos veces en la época republicana, Taquile fue utilizada como lugar de reclusión para presos políticos. Tuvo una pequeña guarnición de soldados para cuidar a los reclusos y muchas veces fue asolada por fuerzas militares que buscaban rebeldes políticos, sobre todo comunistas.

Pero cabe destacar un hecho de gran trascendencia. Desde la primera ocupación de la isla por propietarios alienígenas, mantuvo cada familia lo que después sería su propiedad básica: la vivienda, un pequeño terreno a su alrededor, unos arbustos circundándola y unas cuantas parcelas de tierra diseminadas en los diversos "suyo" de la isla. El resto lo constituían las haciendas y eran colonos de ellas según la ubicación de su vivienda. También en parte la legislación española amparaba esta propiedad básica. Tan fuerte es el apego a ella que, cuando se produjo la compra y adueñamiento de las tierras por los mistis, hubo cierto respeto entre ellos a normas de ocupación tradicionales, todos eran conscientes de que unas familias tenían derecho, más que otras, a determinadas parcelas en cada uno de sus seis suyo.

Amantani, la isla vecina, con mejores tierras y tan codiciada por ello y por la belleza de su paisaje tuvo siempre a sus propios dueños propietarios foráneos viviendo con ellos. Los isleños todo el tiempo tuvieron a sus amos frente a frente, a pesar de que era temido viajar por el lago. Esta situación provocó grandes roces que repetidas veces culminaron en levantamientos de los indígenas, que más de una vez mataron a los propietarios de fuera, a lo cual contribuyó el excesivo abuso de éstos y la densa población aborigen.

En Taquile la situación fue diferente, era muy lejana, el viaje a ella siempre fue considerado peligroso, tal vez si los actuales propietarios Antonina Cuentas y Martín Fernández sean los que hayan vivido más tiempo continuo en ella en toda su historia, casi 30 años. Generalmente los dueños encargaban a un cuidador mestizo o isleño, su kipu, o iban solo para la cosecha año tras año y raras veces para la siembra. 
Cuando llegamos a Puno en 1950 para iniciar este estudio, indagamos datos exactos sobre la isla y en gran parte lo que constatamos fue descubrir cierto temor a ella, sólo un antiguo preso político y un pintor alemán la conocían y su versión fue lo más alentadora que pudimos imaginar. En Puno existe en general un marcado miedo a las islas por el peligro del lago y por el contacto con los indígenas, bien sea por el tifus o porque no interesan o por temor a desaparecer. Esto siempre pasó en Taquile, los isleños guardan el recuerdo de contadas visitas y sólo por horas o a lo más uno o dos días. Es importante recalcar este aislamiento a que estuvo sometido Taquile, lugar ideal según los políticos para una cárcel política o un reformatorio. El gozar de ese aislamiento, también, les otorgaba cierta autonomía, lo cual los afianzaba en sus derechos de propiedad. Cuántas veces en esos siglos aprovecharían íntegramente de ella en su beneficio, verían que no sucedía nada en la economía o vida de los propietarios "de fuera" cuando así sucedía, lo que era contrario para ellos cuando los productos salían fuera de la isla.

Así fue surgiendo un clamor por la propiedad, que ha constituido durante muchos años la única meta de su existencia y por la cual lucharon duramente hasta su consecución, lográndola antes que Amantani, lo que para el taquileño constituye una proeza, de la cual se jactan. Prudencio Huata, al respecto me decía una vez sentados en lo alto de la isla: "nosotros, así atrasados, pobres, tenemos títulos de nuestras propiedades, los de Amantani no". Pero, no solamente la pujanza de un grupo de ellos y especialmente de un hombre, Prudencio Huata, hicieron posible este hecho, sino que además influyeron otros factores: la amistad con los presos políticos (1921-24), surgida a pesar de la vigilancia-policial, y los múltiples servicios que los indígenas les prestaban hicieron nacer cierta hermandad entre ambos oprimidos, lo que originó la vinculación entre Prudencio Huata y uno de los presos políticos que más tarde llegó a ser Presidente de la República. También, la benevolencia y la posición ideológica del doctor Jacinto Zúñiga Béjar, Vocal de la Corte de Puno y la poca importancia económica que Taquile significó para sus dueños, los "hacendados" puneños estaban disminuidos y tenían más dificultades que productos, tifus que la asolaba, prisión política que les restringía su usufructo y posibles levantamientos de indígenas que hacían peligrar sus vidas.

Prudencio Huata viajó a Lima en 1930 a visitar a su amigo el Presidente de la República, general Luis M. Sánchez Cerro, y a pedirle el cumplimiento de sus promesas: "la tierra será de ustedes". Su viaje y su odisea fue apasionante, toda una novela. Regresó nuevamente en 1932 y cuando iba a conseguir la expropiación de la isla a favor de los indígenas, feliz de regresar con esa noticia a Puno al descender del tren que lo traía de Arequipa se entera que su amigo el Presidente había sido asesinado. Prudencio tuvo que refugiarse fuera de la isla y Taquile fue asolada vivienda por vivienda por fuerzas policiales en busca de rebeldes. (En el artículo del autor "La coyuntura del Perú de hoy", publicado en el libro Perú: Hoy. Siglo XXI editores, México, 1971, en la página 338 describo con mayor detalle este apasionante viaje de Prudencio Huata a Lima).

Desilusionados los taquileños esperaron hasta que el 22 de junio de 1937, después de grandes peripecias, el doctor Jacinto Zúñiga mandó llamar a un grupo de seis isleños y con ellos perfeccionó un contrato de compra-venta de las propiedades que poseía en Taquile por la suma de S/. 1,500.00 pagaderos a plazos y en la forma que ellos pudieran. De este modo coronaron los taquíleños una ansiada ambición. Pero, la batalla no estaba aún ganada. Fueron entregando el dinero en armadas sucesivas y recibiendo comprobantes por cada una de ellas en la forma siguiente: 
22 de junio de 1937

30 de junio de 1937

19 de agosto de 1937

08 de septiembre de 1937

25 de enero de 1938

21 de abril de 1938

10 de julio de 1938

14 de octubre de 1938

10 de enero de 1939
S/. $\quad 120.00$

S/. $\quad 100.00$

S/. $\quad 100.00$

S/. 200.00

S/. $\quad 100.00$

S/. $\quad 180.00$

S/. 120.00

S/. 180.00

S/. 260.00

\section{Total S/. 1,360.00}

El saldo de 140 soles fue entregado al doctor Zúñiga Bejar una mañana temprano cuando estaba por viajar en tren a Arequipa, motivo por el cual no pudo otorgarles recibo, pero les prometió hacerlo a su regreso. Al regreso esperaron ansiosamente la celebración de la escritura de venta conforme al acuerdo y ofrecimiento del vocal, pero, una vez más, por su enfermedad no pudo realizarse y para desgracia de los taquileños murió sin poder hacerlo antes y con ello frustró la vieja ambición de los isleños y la de él también. Una valla más que pudo dar fin a tanto esfuerzo.

Pero los taquileños no se amilanaron y desde ese año no cesaron un solo momento luchando desesperadamente por el reconocimiento de sus derechos hasta el 21 de mayo de 1942 donde al fin la justicia falló a su favor y les fue otorgada la escritura pública de compra-venta a su favor por vez primera en la isla y en gran parte de las comunidades del lago. Habían logrado ser dueños de sus tierras con títulos saneados. Esta lucha desesperada desde 1939 a 1942, tres años, que no relato en este capítulo de mi tesis doctoral y que guardo para el libro sobre Taquile, es tan largo y complejo como la descripción del proceso de la propiedad Solo cabe mencionar la extraordinaria habilidad e inteligencia de Lino Huata al enfrentarse a los mecanismos legales del Perú oficial durante este periodo tan crítico y decisivo.

Prudencio Huata, el representante de ese grupo de seis taquileños, fue el que dio la mayor suma de dinero y corrió con todos los gastos del juicio y de la empresa; como tal en la repartición le tocó la mayor propiedad con lo cual se convirtió en el mayor propietario de Taquile, a ello agregó la parte que administraba de los Flores y la suya que era relativamente considerable. Su gran prestigio de líder se robusteció con una sólida base económica, lo que en estos últimos años se ha traducido en cierto recelo justificado y en envidia por parte del resto de los isleños.

El estatus de prestigio de Prudencio alcanza a toda su familia, a su padre, su hermano y sus hijos, de ahí que sea esta familia la que está logrando, por vez primera también en la isla, constituir un grupo de indígenas que van adquiriendo el estatus de mestizos. Prudencio a pesar de haber viajado a Lima dos veces no habla castellano.

Lino Huata, el hermano de Prudencio sí habla correctamente castellano. Estudió cinco años en la Granja Taller Salcedo de la Orden de los Salesianos de Puno. Ha estado al igual que su hermano varias veces en Lima. Es muy inteligente y desde 1936 ha sido el líder intelectual de la isla, en su lucha por defender y lograr los títulos de propiedad, en la inteligente y sobresaliente defensa en todas las citaciones judiciales, en ser guía y consejero de su hermano y ahora de su familia y, en realidad, de toda la isla.

Los Huata también han adquirido parte de la herencia de los Cuentas, pero aún quedan otras y es su deseo conseguirlas para acabar con la presencia de los dos pobladores propietarios mestizos que aún usufructúan tierras en la isla. 
Otro grupo de isleños encabezados por Juan de Dios Cruz, está juntando dinero para comprar la heredad de los Borda (tienen ya S/. 3,000.00). Es decir, familias extensas o grupo de familias afines se unen distribuyendo ordenadamente el proceso de adquisiciones de todas las propiedades de gente de fuera juntando dinero poco a poco para lograr su compra. Caso similar sucede en la isla Amantani donde con motivo de la muerte de sus dueños, los isleños por grupos están adquiriendo las tierras a los herederos.

Otros en la medida de sus posibilidades y grado de parentesco con los Huata, van adquiriendo pequeñas parcelas de tierra de los Huata, unas veces con simples recibos y otras con escrituras públicas de compra-venta.

Informalmente, por otro lado, otras familias están comprando tierras a Martín Fernández, uno de los dos herederos de los Cuentas que vive con ellos. Esas ventas son por recibos y oscilan entre 60 a 200 soles. Hasta la fecha han sido realizadas seis ventas.

Como consecuencia de la evolución de la propiedad podemos señalar y precisar los siguientes hechos que constatamos durante nuestro estudio en 1950-52:

1. Cada familia, hay 113 en la isla, trata de conseguir títulos de las tierras que usufructua.

2. Los isleños están reuniendo dinero a fin de adquirir el resto de las tierras en poder de propietarios de fuera.

3. Una familia indígena acapara grandes cantidades de tierras, lo que produce recelo en el resto.

4. Los dueños de fuera han perdido todo su prestigio debido a la disminución gradual de sus propiedades, las que tienden a desaparecer.

Las relaciones de los dos dueños que viven en la isla y los taquileños y la forma cómo viven tiene el siguiente ritmo:

1. Ambos tienen un grupo de familias como sus colonos. Estos siembran y cosechan, cargan y escogen las semillas.

Retribuyen a los colonos con coca, una carga del producto cosechado y al comenzar la cosecha con una watia (papas asadas en horno de tierra).

Utilizan el compadrazgo con la finalidad de obtener servicios y mayor sumisión de los colonos.

Consideran como colonos a las familias que poseen viviendas en sus tierras.

2. Ninguna otra relación de trabajo ni de servicio existe entre ellos.

3. Los dueños mestizos no poseen yuntas, ni arados de ninguna clase. Para roturar la tierra alquilan vacunos, bien sea de sus colonos o de otros isleños.

4. Existe un mutuo respeto entre mestizos e indígenas. La excepción es debido a algún exceso en las fiestas solamente por parte de los isleños.

5. Uno de los dueños vende coca, azúcar, velas y remedios caseros.

6. Los dueños preparan sus alimentos sin la ayuda de nadie.

7. Ambos dueños llevan una vida independiente y hay cierta fricción entre ellos y los indígenas.

8. El nieto de uno de los dueños concurre a la Escuela en igualdad con los isleños.

9. La hija de la dueña bromea con los indígenas lo que motiva que siempre le falten el respeto, pero no provoca conflictos ni reclamos.

10. Uno de los dueños vende poco a poco sus tierras, el otro no y más bien critica esas ventas.

11. Ambos dueños son mirados indiferentemente por los isleños, aunque uno de ellos más bien con compasión. Este asiste a todas las reuniones y fiestas haciéndose convidar comida y coca, interviene en los conflictos, arreglos y reclamos generales de los isleños. Mastican coca en mayor cantidad que los isleños. 
12. Ocupan en las fiestas y en la iglesia, en las que su actitud y comportamiento es igual a la de los isleños, lugar de preferencia al lado de los mandones (autoridades tradicionales).

13. Regalan imágenes a la iglesia y las bendicen realizando igual ceremonial que los isleños.

14. No ocupan ningún cargo religioso en la isla, pero sí fuera de ella.

15. Obtienen préstamos de los isleños: productos, coca, yuntas, kerosene y remedios.

16. Su vida cotidiana es exactamente igual a la de los isleños: vivienda, alimentación, utensilios, menaje, creencias y valores. Su única diferencia radica en el vestido mestizo y en el dominio del castellano.

Hasta aquí la evolución de la propiedad en Taquile. A través de toda su presentación cargada de detalles, fechas y complicaciones de relaciones de parentesco y de entradas inesperadas de herederos o propietarios, he querido ofrecer un relato minucioso que nos dé una idea de su proceso en una comunidad tradicional de la región andina serrana dado, sobre todo, la importancia trascendental que para Taquile tiene la lucha por la propiedad de la tierra y para conocer el mundo rural indígena.

Los valiosos documentos que existen en diversos repositorios, así como en poder de particulares, permiten en el Perú reconstruir para muchas comunidades, haciendas o regiones del territorio el proceso evolutivo de la propiedad desde el siglo XVI al presente. Realizar varios de estos estudios en diversas regiones creo que sería importante para la mejor comprensión de la base de la estructura económica nacional y contribuir a forjar una auténtica sociedad nacional.

Melville Herskovits en su obra Antropología económica (México 1954, p. 283) destaca la importancia de este tipo de análisis al manifestar "Nada indica mejor el realismo, en cuanto al modo antropológico de abordar los fenómenos económicos, que el hecho de que el estudio comparado de sistemas económicos deba recaer tanto sobre los procesos como sobre las instituciones..." y más adelante concluye citando a Frank H. Knight (Limitations of Scientific Method in Economics. Nueva York, 1924). "La perspectiva lograda en el estudio de la vida económica de las sociedades no industriales nos revela claramente que las instituciones económicas son donde quiera el resultado final de los procesos económicos, sin cuyo estudio no podríamos llegar a comprender debidamente las instituciones que se desarrollan como resultado de su funcionamiento" (p. 283).

\section{La situación actual de la tenencia de la tierra}

Un documento recibido al momento de escribir este capítulo de mi tesis doctoral, las informaciones que constantemente nos envía Lino Huata desde Taquile, así como las conversaciones con los taquileños que llegan a Lima, nos permiten ofrecer como parte final de este estudio la situación actual de la evolución de la propiedad en Taquile. Igualmente hemos podido conseguir, después de haber escrito la primera parte de este artículo una apreciación del área de la isla. Estas informaciones sirven de base al análisis que presentamos a continuación.

El área total de la isla, de acuerdo a las cartas geográficas militares es de $7.54 \mathrm{~km}^{2}(754$ hectáreas) y su población en 1952 era de 640 habitantes, según el censo que realizamos en esa fecha. Es decir una densidad de 85 habitantes por $\mathrm{km}^{2}$.

El Director de la Escuela de Primer Grado de la isla, señor Juan Sánchez, realizó en 1956 un minucioso análisis, tendiente a conocer la cantidad de tierra que cultivaba cada isleño. Este trabajo fue alentado por el suscrito quien a través de Lino Huata sugirió la necesidad de su ejecución. El año pasado el profesor Sánchez me entregó una copia de dicho catastro empírico que, con ayuda de los alumnos, había levantado. 
El título del manuscrito de 122 páginas es "Relación minuciosa de la propiedad del suelo labrantío de la isla Taquile para el libro del doctor José Matos Mar".

El trabajo es de una utilidad insospechada. A fin de uniformar una medida tendiente a conocer la superficie de las parcelas ha utilizado el cálculo o estimación tradicional de los taquileños. Una parcela sembrada con tres libras de semilla de papas tiene aproximadamente una área $\left(100 \mathrm{~m}^{2}\right)$, con media arroba de papas cuatro áreas $\left(400 \mathrm{~m}^{2}\right)$ y con una arroba ocho áreas $\left(800 \mathrm{~m}^{2}\right)$. Esto es en gran parte el sistema que practican los isleños, tanto para sus transacciones de compras de terrenos, como para calcular sus siembras. Sobre esta base el profesor Sánchez preguntó a cada isleño, en el lugar de sus chacras, cuánto calculaba que sembraba en cada una de sus propiedades y con esta respuesta ha podido ofrecer el primer intento de catastro de la isla. Además, en su lista ha indicado el lugar de ubicación de la propiedad, la cantidad de andenes y sus clases: andenes en distintos tablones, irregulares y parcelas en pendiente, la cantidad de tierras poseídas por los grandes propietarios que llama hacendados, y entre los cuales incluye a Prudencio Huata, y las que son de propietarios de sus tierras con títulos expedidos en las notarías puneñas. Es decir, nos ofrece un trabajo realmente minucioso.

De él extraigo los datos principales que se relacionan con la tenencia de la tierra, dejando su análisis posterior para un trabajo especial.

Un cuadro general de la situación es la siguiente:

1. Los dueños de fuera (mestizos) poseen: Familia Cuentas

Familia Borda

Martín Fernández

Antonina Cuentas

2. Prudencio Huata y su familia:

Prudencio Huata

Pedro Huata (padre)

Lino Huata

Bonifacio, hijo de Prudencio

3. 66 personas tienen propiedades con títulos registrados en las notarías de Puno con un total de 30 hectáreas, a las que para nuestro cálculo general debemos reducir 3 hectáreas, que están incluidas en las pertenencias de la familia de Prudencio Huata, gran parte de la cual tiene titulación.

27 ha.

4. El resto de las isleños utiliza:

Total:

400 ha.
29.9 ha.

13.4 ha.

11.2 ha.

3.4 ha.

2.9 ha.

33.1 ha.

15.9 ha.

8.2 ha.

6.2 ha.

2.7 ha.

480.6 ha.

Esto nos indica que casi el $65 \%$ de la isla es utilizada para agricultura, y de este $65 \%$ la distribución en cifras relativas es la siguiente: 
1. Propiedad de los mestizos $6 \%$

2. Propiedad de la familia Huata $\quad 7 \%$

3. Propiedad con titulación $5.5 \%$ (que con las que posee la familia Huata debe llegar al 10\%)

4. Propiedad del resto

Total:

$100.00 \%$

Este cuadro muestra claramente el actual proceso de la propiedad en la isla. Confirma con cifras que el mayor propietario es la familia de Prudencio Huata y que los dueños de fuera sólo retienen una proporción bastante reducida, en la cual la pertenencia de la familia Cuentas es la más importante, siguiéndole la de la familia Borda, sumando entre las dos 29.9 ha. Las propiedades de la señora Antonina Cuentas y del señor Martín Fernández son reducidas, apenas llegan, sumándolas a 6.3 ha. Lo notable con respecto a la situación de 1952 es el incremento de los isleños que tienen propiedad con titulación, llegando a 66 personas que corresponden a unas 40 familias básicas o sea que más del $40 \%$ de las familias, que son 113 tienen su propiedad debidamente refrendada y la extensión de ésta varía desde 2.6 ha., la mayor, hasta 0.4 ha., las menores. En 1952 solamente unas diez personas tenían títulos. Son múltiples los caminos por los cuales estas 66 familias han logrado adquirir sus tierras: unas con los ahorros obtenidos trabajando en Lima como domésticos; otras con el producto de la venta de sus cosechas, otras trabajando en las chacras en Arequipa.

Este esquema tiene, sin embargo, algunas variantes que es necesario dejar claro. En la propiedad de la familia Huata está considerada la de la familia puneña Solís, que todavía reclama tener derecho a unas hectáreas, motivo por el cual existe un juicio que aún no ha sido resuelto por los tribunales de justicia de Puno, sin embargo Prudencio Huata las utiliza y las considera suyas.

En la propiedad que pertenece al gran conjunto de los isleños, $81.5 \%$ del total, están incluidos los usufructuarios de las tierras de las llamadas haciendas (de los Cuentas y Borda) cuya superficie no es muy grande, tierras que los que la trabajan las consideran como suyas y de sus productos sólo una pequeña parte entregan a sus dueños. Esta propiedad es la que cada familia trata de comprar, hecho que ha significado el incremento hasta llegar a 66 propietarios con títulos legales. Esta situación, por otra parte, irá desapareciendo a medida que sus usufructuarios puedan reunir el dinero necesario para adquirirlos.

Hemos mencionado que casi el $65 \%$ de la isla es aprovechada en la agricultura, pero cabe también mencionar que no todas las tierras son de igual calidad. En el capítulo de mi tesis sobre Agricultura se ha indicado las clases de tierras que ellos reconocen, así como las zonas donde están situadas. Chuñopampa es el suyo donde están las mejores tierras, las otras son de inferior calidad, siendo las más pobres las de las orillas del lago, así como las de los dos suyo que se encuentran en el extremo sur de la isla.

Indudablemente que el trabajo realizado por el profesor Sánchez puede tener errores, pero de todas maneras nos permite tener un punto de partida que no creemos esté muy lejos de la realidad.

En esta forma hemos presentado un esquema evolutivo del desarrollo de la tenencia de la tierra en la comunidad indígena de Taquile, una isla del Lago Titicaca. Asimismo, hemos analizado sus implicancias con respecto a otros aspectos de la vida de la comunidad. A través de este relato el lector podrá apreciar cómo 640 habitantes en una isla del lago, lugar tan aislado y tradicional, están movilizados con toda su potencialidad y posibilidades en 
una lucha por la tierra y como está una comunidad indígena afectada por el cambio cultural y social al que no escapa en estas últimas décadas ningún pueblo, comunidad, aldea o caserío del mundo rural del país. Este estudio antropológico es también una contribución a la etnohistoria para comprender hasta donde fuere posible cómo funcionaba el mundo andino prehispánico.

\section{Características de las relaciones de propiedad y tenencia de la tierra}

Ahora, cabe seguir con la información etnológica y presentar la actual situación en cuanto a las características de las relaciones de propiedad y tenencia de la tierra en la vida de los indígenas taquileños.

- Relaciones interpersonales. Las estrechas relaciones interpersonales de los taquileños son constantes como en todas las comunidades andinas y guardan relación con la pequeña extensión de la isla y el género de vida que ella les impone, el pastoreo, las faenas agrícolas, la recolección, la pesca, los viajes, etc., de manera que unos y otros conocen sus dificultades y cualquier suceso por íntimo que sea es compartido por todos, lo que crea un control social efectivo. El estudio de la propiedad aclarará aún más los diversos sistemas de relaciones interpersonales.

- Propiedad corpórea. Las familias son dueñas del canchón, (como en la época antigua), de tierras de cultivo, animales, chozas o refugios en varios suyo, árboles como el kolle y el eucalipto, objetos de uso personal: ropa, adornos, vestidos de fiesta, utensilios agrícolas y de pesca, instrumentos musicales, telares, menaje de cocina, cestas, objetos mágicos. La posesión de estos bienes muebles e inmuebles, o sea la propiedad corpórea, es lo que determina la pobreza o riqueza de los isleños, porque ellos son los elementos deseables por los individuos, debido a su uso, utilidad, valor y posibles de poseer.

Los animales domésticos constituyen su mayor fuente de ingresos. El kolle que plantan alrededor de cada canchón constituye también riqueza. El dueño es quien lo planta y es parte fundamental en el conjunto de los bienes materia de herencia, por eso tiene gran importancia poseerlos debido a su potencialidad productiva, porque les sirve para conseguir dinero vendiendo su leña en Puno, para construir los techos de sus casas y para la fabricación de botes y sus accesorios. El eucalipto, que apenas tiene unos 20 ó 30 años de introducido, lo poseen solamente algunas familias, ahora está siendo considerado como una riqueza, y en esto viene el ejemplo de Amantani y del alto precio que la familia Borda-Solís les quiere cobrar por su propiedad, debido a que posee más de 100 árboles de los primeros plantados en esa isla. Esto ha determinado que muchas familias tengan en sus patios en ollas de barro almácigos de este árbol. En Amantani, dentro de unos cinco u ocho años, el número de eucaliptos será considerable, pero a ello contribuye además otro móvil que es el de la carencia de leña para combustible.

La leña y el agua son de propiedad comunal, así como las tierras de pastoreo (wasara). Debido a la abundancia de leña, buena parte de ella la venden en Puno en forma individual; pero, a pesar de que se traduce en dinero, no hay hasta ahora acaparamiento ni conflicto alguno por su recolección. Últimamente, los mandones (autoridades tradicionales) han indicado en sus reuniones comunales que no deben recolectarla tan profusamente porque puede acabarse y les señalan el caso de Amantani. No hay viaje a Puno en que los botes no lleven dos o tres quintales de leña.

- Propiedad pública. La propiedad pública la constituye la iglesia, la capilla, la escuela y sus tierras, la casa cural, los caminos, los muelles, las estructuras en sus cerros rituales especialmente en el cerro Mulusina y otros donde generalmente están ubicadas las ruinas arqueológicas a las que consideran las moradas de sus antepasados y sus 
apachetas lugares sagrados a los cuales hay que reverenciar porque en ellos habitan los huihuac, espíritus.

- La propiedad incorpórea. Las ideas, destrezas, invenciones o habilidades, creaciones, canciones, danzas, motivos decorativos, mitos, magia, modos de curar, etc., es decir la propiedad incorpórea, o sea la que se refiere al conocimiento general a todos y la propia ecuación personal es común. Existe diferenciación debido a condiciones especiales de las personas y cuando esto sucede, como en el caso de los curanderos o jampicos, o de los hechiceros, sus conocimientos se traducen en dinero. El poseer cualidades intangibles les da la posibilidad de obtener recursos económicos. Pero, en Taquile este tipo de propiedad casi no tiene importancia como en otros grupos. Lo que sería propiedad absoluta o sea que no acepta ninguna limitación: nombres personales, danzas, canciones, mitos, actos ceremoniales, es considerado como bien común. De lo que si son muy conscientes es del prestigio que cada uno tiene por sus habilidades, conocimientos e inteligencia, tal el caso sobresaliente de Lino y Prudencio Huata y el de algunos jefes de familia hábiles artesanos, bailarines o tejedores.

- La propiedad privada o individual. Se incrementa por el esfuerzo o capacidad económica, sin que lleguen a poseer un gran bagaje; simplemente tienden a lograr lo necesario para sus necesidades básicas. No obstante, los viajes les enseñan nuevos productos de la vida moderna que muchos tratan de adquirir, algunas veces movidos por la novedad antes que por la utilidad que puedan prestarles.

El prestigio social o una recompensa no material comienza a motivar la posesión de determinado bien; pero, en general, la norma que rige su actitud hacia la propiedad es el valor práctico y productivo de las cosas, el que acumula mayor riqueza adquiere un estatus social de privilegio.

- Préstamos. Las propiedades menos estrictas y que pueden proporcionar en préstamo sin mayor objeción la constituyen los utensilios caseros y el dinero. En cambio, nunca prestan las tierras porque ésta constituye la propiedad fundamental, que es de cada uno y de nadie más, para ella no conciben el préstamo ni el alquiler, aunque sí pueden venderla como está sucediendo recientemente.

Cuando prestan objetos personales lo hacen sin esperar retribución, únicamente por amistad o parentesco. Recientemente han comenzado a cobrar un flete por los vestidos de fiesta (10 a 20 centavos por una pollera, un sombrero o un adorno de fiesta) debido a la escasez que hay en el mercado de Puno y a su elevado costo que está al margen de sus posibilidades económicas. Existen préstamos de herramientas y utensilios, especialmente para fiestas o en caso de muerte, en el velorio, bajo el sistema del ayni que corre generalmente a cargo de los familiares.

El préstamo de dinero (manurikuy) y de víveres (ayni) es usual. El primero lo hacen sin intereses y oscila entre 10 a 20 soles; en algunos casos llega a 100 soles. Recientemente han prestado a sus vecinos de Amantani una fuerte suma para la adquisición de tierras. Los víveres son prestados bajo el sistema de ayni o sea con la condición de devolución, significa una ayuda especialmente cuando alguna persona tiene mala cosecha. $\mathrm{Su}$ préstamo puede ser a largo plazo, no existiendo una norma que regule estos servicios que consideran como una obligación. Muchas veces ocurre que algunos deudores mueren sin haber devuelto el préstamo y ni los hijos ni la viuda asumen la obligación de la deuda. Generalmente muerto el interesado desaparece la deuda sin que ello impida nuevos préstamos a la familia cuando ésta lo requiera. Estos préstamos incluyen toda clase de productos, papas, ocas, maíz, cebada, etc. 
Otro tipo de préstamo generalizado es el de las chozas para los pastores. En tiempo de lluvia, cuando deben ir a pastar lejos de su vivienda, en los extremos de la isla, solicitan las chozas que existen en esos parajes y nadie a quien le sea solicitado piensa en negarla. El pedido no se extiende más allá de un simple albergue por unas cuantas noches.

Las familias que poseen más de una vivienda acostumbran prestar los cuartos-depósitos que tienen desocupados a fin de que guarden sus cosechas aquéllas que no los tienen o a quienes no les alcanza el que poseen. Lo que no entra en los préstamos y nadie lo solicita son los depósitos de las viviendas permanentes donde habitan. Tampoco se da el caso de que alguien preste su vivienda para vivienda de otra familia.

Existen algunas personas que no les gusta prestar, negándose rotundamente cuando alguien les solicita algo. Esto es considerado como falta de voluntad y se les considera personas egoístas, pero son casos excepcionales. El Hilacata que nos informa sobre esto, nos dice: "mire, el sombrero que llevo puesto, por el cargo que desempeño, me lo ha prestado mi cuñado sin ninguna dificultad". La generosidad es el patrón general que anima todas las transacciones de préstamo y nunca abusan de ella. Entre familiares es mayor el desprendimiento. Ningún padre dejará de comprar coca en cantidad suficiente para toda su familia, aún para el uso de los hijos casados que vivan con él. Asimismo, los hijos que guardan profundo respeto al hogar no hacen abuso de ese derecho.

En el seno de la familia comparten indistintamente el uso de los utensilios y alimentos en forma común, sin tener en cuenta quién sea el dueño de los mismos. Sin embargo, como dice Kardiner (El individuo y su sociedad, México, 1945, pp. 248-249), se confirma la propiedad individual tan pronto como se trata de vender las cosas, o en caso de destrucción o daño.

- La educación. Margaret Mead (Sexo y temperamento, Buenos Aires, 1947, p. 64) en su estudio de los Arapesh de Nueva Guinea nos describe la relación entre la propiedad y la educación de los niños hacia ella. De su estudio tomamos algunas ideas que se presentan igualmente en Taquile. La enseñanza que reciben los niños los condiciona desde sus primeros años a tener respeto por la propiedad ajena y los estimula a otorgarles un sentido de seguridad natural sobre la de su familia. Son reprehendidos con cierto vigor cada vez que dañan la propiedad ajena y es el padre el encargado de ello. Esta educación no está orientada como en la comunidad de Tupe (Yauyos) a acentuar lo tuyo y lo mío en forma terminante; se deja sentir esta influencia pero en forma moderada. En la vida familiar todo está al alcance de ellos, aunque siempre bajo el control paterno o materno y las restricciones son fuertes cuando se trata de utilizar determinados objetos muy personales de los padres. La educación tiende desde niños a hacerles conocer ampliamente lo que después será de ellos y el cuidado que deben otorgarle; los va normando a acentuarles su propiedad privada y a respetar la ajena; al mismo tiempo a que reconozcan ciertos usos comunes sobre los que tienen derechos y obligaciones.

- Dinero. La posesión del dinero tiene por finalidad máxima adquirir nuevas tierras en las familias más acomodadas y, naturalmente, sirve para la compra de los utensilios y productos indispensables. El interés por poseerlo se acrecienta cada vez más porque saben que así pueden lograr un mejor estatus económico. Actualmente la motivación fundamental que determina la migración a la zona vecina de Puno, Moquegua, Arequipa y Lima es juntar dinero para adquirir tierras.

- Conflictos por la tierra. Los pleitos por tierras casi no han existido entre los isleños, sin que esto signifique, dado el desenvolvimiento que está adquiriendo la propiedad, que no surjan en el futuro. Actualmente nadie concibe sembrar en andén ajeno aun 
cuando esté desocupado largos años. El respeto por la propiedad es entre ellos nota fundamental, lo que no ocurre con la que pertenece a los dueños de fuera.

- La propiedad de las tierras. Es exclusivamente de los hombres debido a su estructura social. La residencia patrilocal y la posición de privilegio que ocupan los hombres determinan esta situación. Ninguna mujer es propietaria de tierras, de viviendas o de cosechas. Hay exclusión de las mujeres para la posesión de títulos de propiedad. No obstante este hecho, el hombre no puede disponer de sus pertenencias sin consultar con su mujer y sin contar con su consentimiento o mutuo acuerdo no realizan ninguna transacción. Muchas veces hasta para viajar a Puno es necesario el acuerdo entre ambos y dejan de hacerlo cuando la mujer aduce buenas razones, tales como exceso de trabajo, porque existe poco que llevar a vender o que por el momento no necesitan adquirir nada. Los hijos tampoco pueden vender parte de la cosecha sin la aquiescencia de los padres. Cuando muere el padre las hijas reciben aproximadamente una cuarta parte de las propiedades, parte mínima. Son los hijos varones quienes reciben la mejor parte de lo que fue la propiedad de sus padres. La pequeña parte que recibe la mujer pasa a ser propiedad de su marido.

- Formas de adquisición. Las tierras se adquieren por herencia, apropiación o compra. La primera forma es la que siempre ha normado la propiedad de los isleños. La apropiación es más reciente y rige únicamente con las tierras, y en ocasiones con las cosechas de los propietarios de fuera, modalidad esporádica y transitoria. La adquisición por compra es reciente. Las pequeñas ventas entre ellos están en pleno apogeo en estos últimos años. Unos a otros tratan de adquirir o vender pequeñas parcelas de tierra. Así, un andén de unos tres metros de ancho por 10 a 12 metros de largo puede ser comprado en 10 a 15 soles. La compra de la mayor cantidad de tierras se hace por escritura pública en alguna notaría de Puno. En las compras pequeñas es frecuente el uso de recibos. La mayor compra que anotamos en 1953 entre los isleños fue por valor de 300 soles por varias secciones de andenes y fue hecha con escritura pública.

El padrino de bautismo está en la obligación de obsequiar a su ahijado dos varas de bayeta o rijira, un chullo, una camisa, etc., y ocasionalmente el regalo puede consistir en una oveja o un andén, ésta sería una forma eventual de adquirir tierras.

Las compras de tierras son exclusivamente hechas por los indígenas. Lo nuevo es la venta que hacen algunos indígenas acomodados a los pobres. La fuente general de venta son las propiedades de los mestizos antiguos hacendados. Por este hecho nadie concibe en la isla que un foráneo, indígena o mestizo, adquiera tierras. Solamente un indígena aymara casado con una taquileña ha sido aceptado por el grupo, pero él no compra tierras, sino que usa las que su mujer heredó. Todo esto indica el afianzamiento de la propiedad privada y el acomodo del grupo a su sistema comunal tradicional. El control social del grupo respecto al uso de la propiedad de las tierras se manifiesta claramente en la existencia de un mandón (autoridad) denominado Alcalde de Campo, que vela por el cuidado de que se use y se cultive bien la tierra y, además, en la víspera del rito de Mulusina las autoridades tradicionales en reunión pública increpan o castigan a quienes hayan atentado contra la propiedad ajena o hayan utilizado mal la suya, sin que esto sea considerado una intromisión, sino más bien un deber del poder político. Todo ello nos hace pensar que todavía en la isla la propiedad es considerada como una institución que la comunidad debe controlar y cuidar.

- El concepto de propiedad. Otro hecho importante es el concepto que tiene el taquileño acerca de la propiedad. Todavía no la consideran como puramente individual sino fundamentalmente como propiedad familiar: son las tierras de los Huata o los Mamani 
y no de Prudencio Huata o Tomás Mamani. Todo el grupo participa de esta idea, de ahí que la familia juega un papel preponderante en la tenencia de la tierra y debido al control social de la comunidad hacia ella se percibe claramente en este análisis de la propiedad que familia y comunidad son fuentes de seguridad en el grupo, situación que parece ser el patrón cultural en sus relaciones sociales.

- Herencia. Cuando una persona fallece sus pertenencias personales no se destruyen, sino que se regalan entre aquellas personas que ayudan voluntariamente durante el velorio y el entierro. El resto queda para la familia.

Los hijos son los herederos de sus padres. El reparto de la propiedad se efectúa a medida que ellos van casándose. A las hijas mujeres, como ya se ha indicado, les corresponde una ínfima parte. Los hijos a medida que forman una nueva familia, reciben de sus padres las tierras necesarias para su sustento, además de los implementos y utensilios indispensables. Asimismo, les construyen una casa al lado de la paterna. Toda esta repartición se hace a ojo de buen cubero, pero por lo pequeño de la heredad, se realiza con sensatez y noción de la igualdad. El padre reserva la casa donde habita, así como las tierras y el capital en efectos que le serán indispensables para vivir hasta el fin de sus días. Esta es la forma del reparto de propiedad establecido por su patrón social y que hemos observado personalmente.

Cuando el padre muere dejando hijos menores, es el Kuraj-hijo mayor-el encargado de velar por el cumplimiento del reparto de la herencia entre los hermanos menores. Queda como un padre para ellos y su deber es cuidarlos y atenderlos como lo haría su propio padre. Aún en el caso de que dejara viuda, el hijo mayor es siempre el encargado del reparto de la herencia, haciéndose también cargo de la madre.

Lo interesante en el patrón que rige la herencia es la posición del hijo menor, el chana. Después del reparto de la herencia a todos sus hijos, incluso al chana, el padre se reserva la casa de la familia y como hemos indicado los bienes necesarios para subsistir hasta el fin de sus días. Pero, la parte que conserva el padre hasta su muerte la hereda el chana. Muchas veces ella ha sido aumentada por los años y por la laboriosidad del padre. A cambio de esto, el chana tiene la obligación, soltero o casado, de cuidar a sus padres hasta su muerte, adquiriendo una obligación y un privilegio, porque es el único heredero de esa propiedad, la básica, el núcleo de la propiedad que viene por herencia desde tiempos muy remotos y que no puede desmembrarse.

El chana añade a su herencia esta nueva propiedad a la muerte del padre, a cambio de cuidarlo en caso de incapacidad en el trabajo o por vejez no poder cultivar sus tierras, velando porque no le falte nada, atendiéndolo solícitamente y al morir cubrir los gastos que ocasione Además, si esta viva la madre la debe cuidar hasta que muera.

Sucede muchas veces que el menor de la familia es mujer, en este caso ella no es considerada chana, ya que de ser así no se conservaría la propiedad tradicional de la familia porque, de acuerdo con su organización social, la mujer forma parte de la familia del marido, siempre la consideran como un "pasajero" según expresión de los taquileños. Cuando esto sucede, es el kuraj (el mayor) u otro hijo quien debe asumir las obligaciones del chana y ganar así sus privilegios.

Cuando el chana es menor de edad, el hermano mayor asume la obligación de cuidar a sus padres y en caso de muerte de ellos, debe hacerse cargo de toda la responsabilidad que ello signifique hasta que el hijo menor llegue a la mayoría de edad, respetando celosamente los derechos de éste a su herencia como chana, además de la que le corresponde.

La hija en caso de ser única, no hereda el total de bienes del padre. En este caso son los tíos paternos los herederos. Ellos reparten los bienes respetando los derechos 
establecidos para la hija, la cuarta parte, aunque mejorándola. Un solo caso hemos registrado en el sentido contrario de que una hija herede íntegramente a su padre.

Las disputas por herencia se presentan cuando los padres al morir no dejaron repartidos sus intereses por descuido, muerte repentina o por alguna circunstancia especial, como mala fe de los hijos, abandono de la casa paterna, ambiciones personales, etc. El patrón para el arreglo de estas dificultades es el acuerdo entre ellos, sin intervención de extraños. Si ellos no llegan a ningún acuerdo intervienen los mandones, que hacen el reparto después de escuchar a las partes, siendo su fallo definitivo. No se da el caso de que acudan a personas o autoridades de fuera para el arreglo de tales disputas. Muchas veces cuando una persona está moribunda, o siente acercarse el fin de sus días, llama a algún familiar o compadre para que actúe como testigo y encargado de repartir la herencia, dejando todo distribuido según su deseo.

- Extensión de los terrenos de cultivo. No existe una medida general para conocer la extensión de las tierras. Se venden o compran, teniendo en cuenta dos criterios: la cantidad de semilla que pueden recibir y la "vista" o apreciación que hacen de su posible valor. Una parcela sembrada con tres libras de papa debe tener aproximadamente un área de $100 \mathrm{~m}^{2}$ y con una arroba de papas $800 \mathrm{~m}^{2}$. Cuando el terreno es irregular, parte en andenerías, parte en pendiente, etc., es su apreciación la que señala su valor. Ambos criterios son decisivos para fijar el valor de una parcela. Este depende, además, del rendimiento, ubicación y facilidad de cultivo del terreno; de allí que las tierras que miran al este y sobre todo las situadas en la hondonada de Chuñupampa son las de más alto valor.

- Distribución de la propiedad. Las 113 familias poseen sus parcelas de cultivo diseminadas en los seis suyo de la isla. Todos tienen siquiera un andén en cada uno de ellos. Este hecho es una clara muestra de la supervivencia del sistema tradicional del reparto de la tierra. En los mapas adjuntos puede verse claramente a través del ejemplo de tres familias de diferente nivel esta situación. Las principales familias tienen sus propiedades en lugares perfectamente establecidos desde época inmemorial, de manera que en los seis suyo la distribución de la propiedad se presenta como manchas: esta sería la propiedad nuclear diseminada por doquier.

Por los matrimonios, las compra-ventas y el actual proceso de adquisición no es posible ofrecer un cuadro de la verdadera distribución de la propiedad. Lo remarcable es que las mejores tierras están ahora en poder de los indígenas más acomodados, o sea de unas pocas familias.

Todas estas características que venimos exponiendo no han sufrido todavía un quebranto notable frente a la nueva situación motivada por la paulatina desaparición de la propiedad mestiza y su adquisición por los indígenas. Pero, en sus estructuras fundamentales ya está iniciándose un cambio que afectará la organización general de la vida en la isla. No debemos olvidar que entre "la propiedad y la vida social, existe una intimidad estrecha, un materialismo biológico, cada una da vida y forma a la otra" (Lowie, Robert H. Social Organization, London, 1956) y que "las ideas de la propiedad tiñen todas y cada una de las fases de la vida social", (p. 129). 


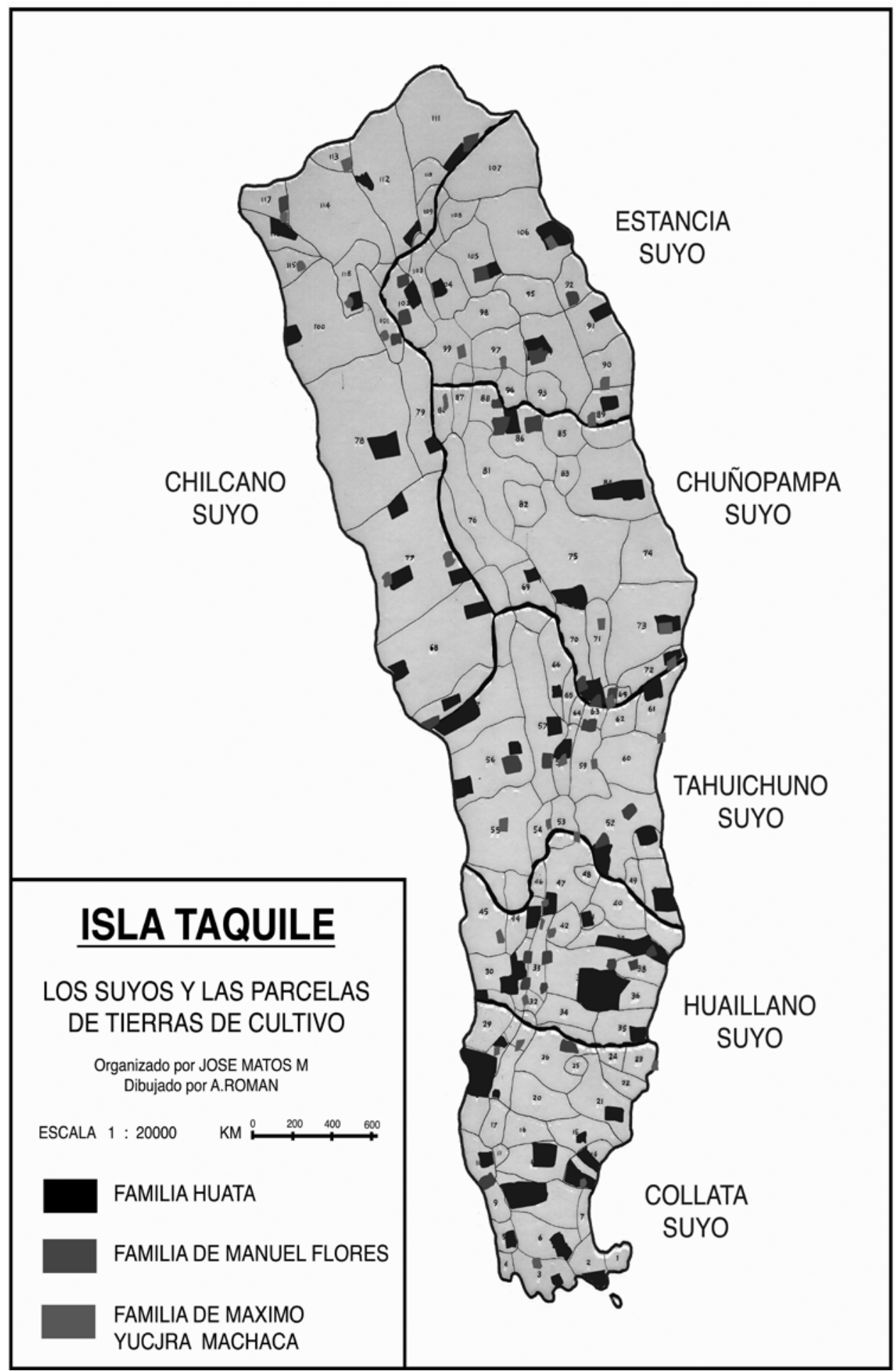

FIGURA 1. MAPA GENERAL DE LAS FAMILIAS Y SUS PARCELAS. 


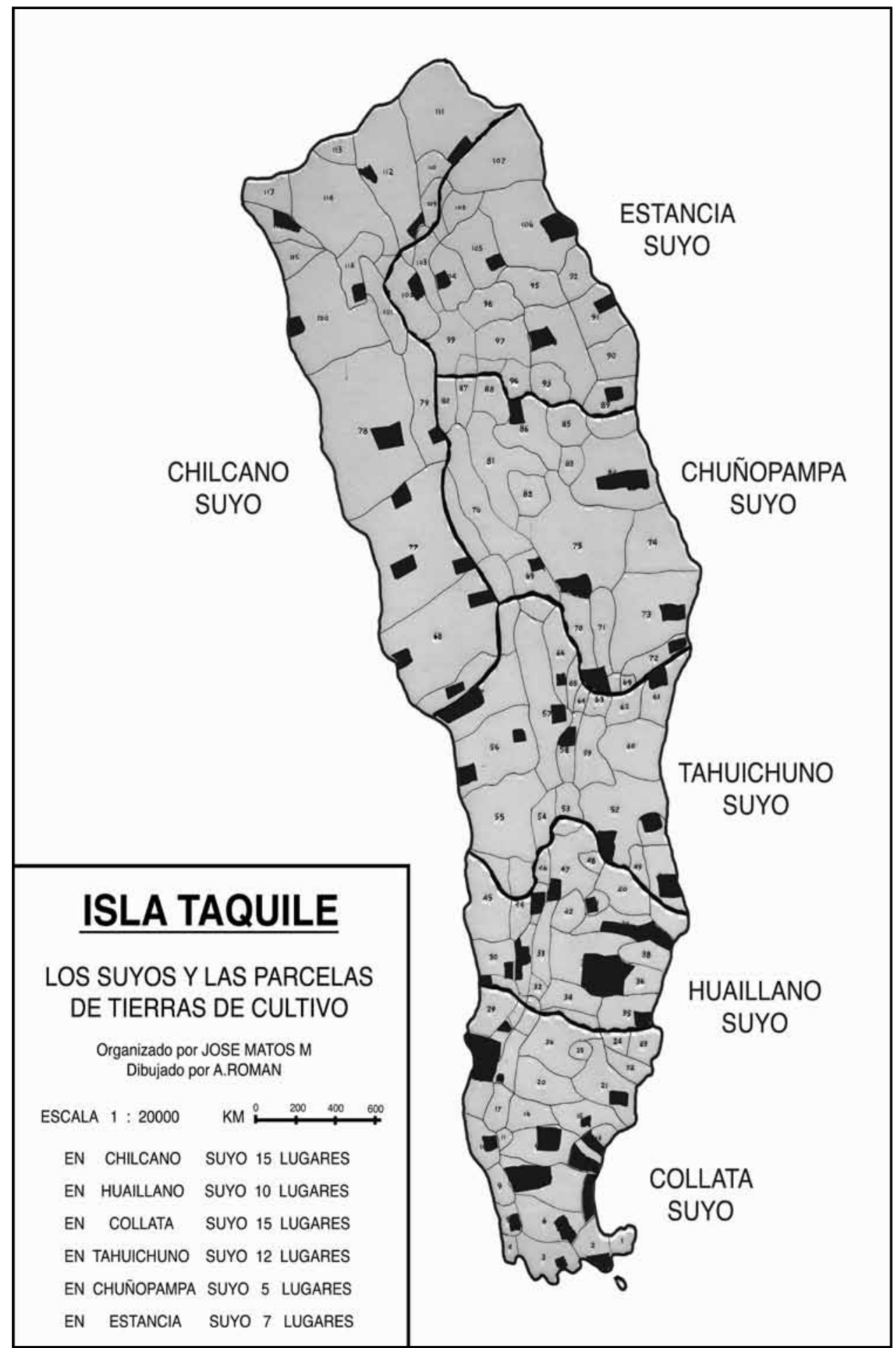

FIGURA 2. LUGARES DE CULTIVO DE PROPIEDAD DE LA FAMILIA HUATA, LOS MÁS ACOMODADOS. 


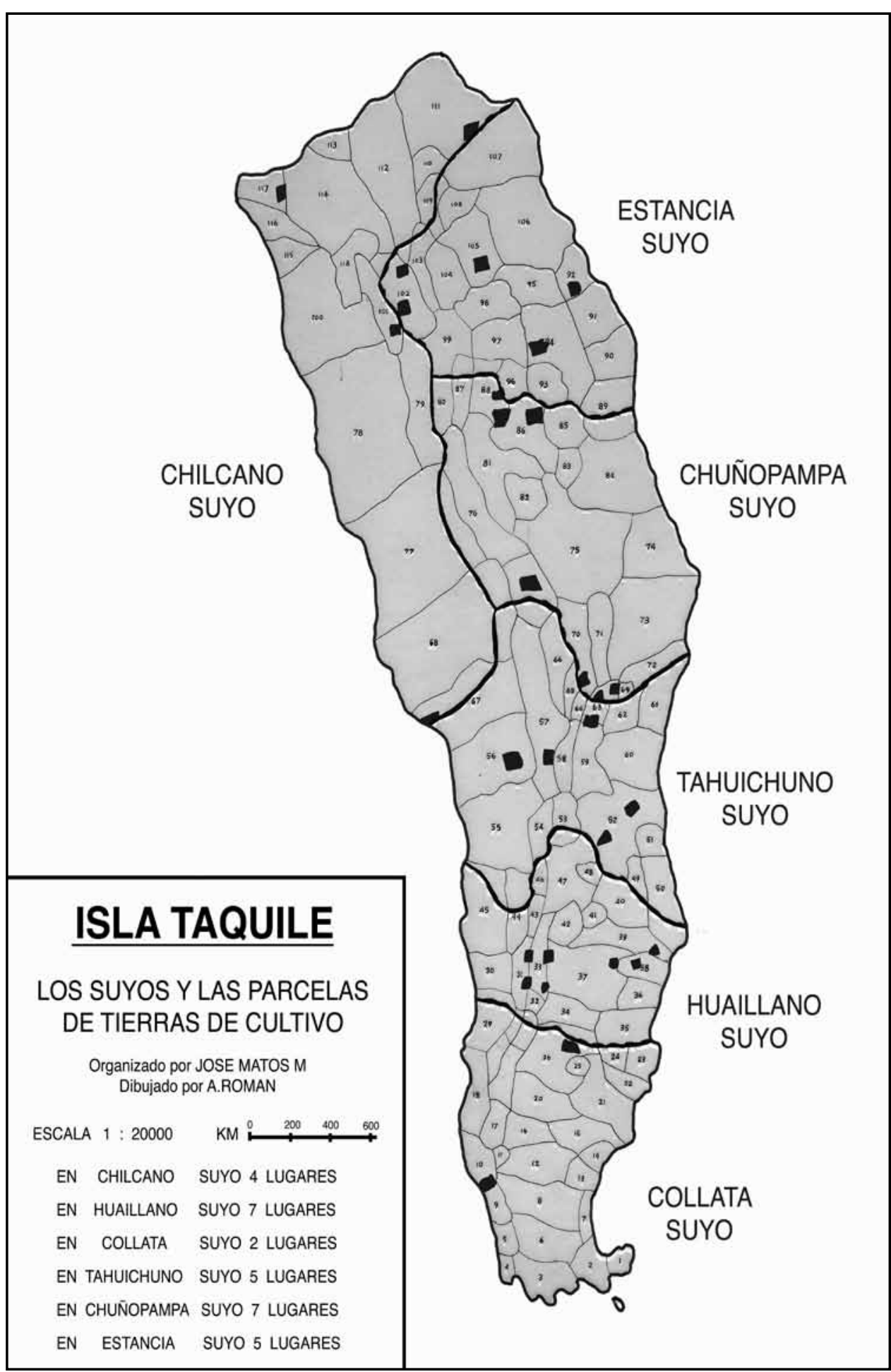

FIGURA 3. LUGARES DE CULTIVO DE PROPIEDAD DE LA FAMILIA DE MANUEL FLORES. 


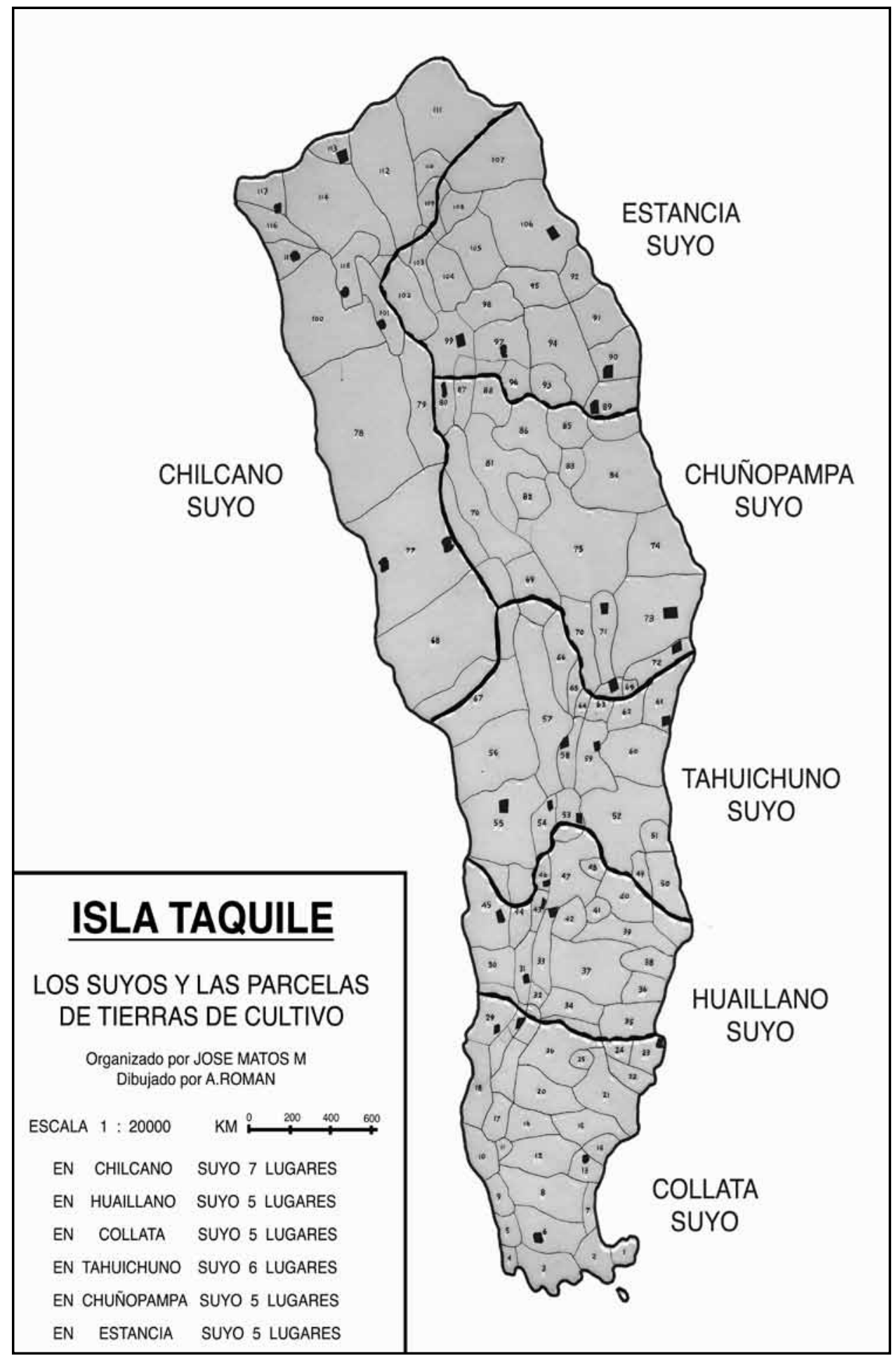

FIGURA 4. LUGARES DE CULTIVO DE PROPIEDAD DE LA FAMILIA DE MÁXIMO YUCJRA MACHACA. 


\section{La propiedad y la estructura social}

Hasta hace 10 años había dos grupos bien definidos: los patrones o "mistis" y los indígenas. Los primeros eran los pocos mestizos puneños, dueños de tierras o "haciendas" en la isla. Se reducían a unas dos o tres familias con una veintena de miembros, de los cuales dos o tres vivían en forma temporal o más o menos permanente en la isla y que, como patrones, dominaban la vida económica del grupo. El otro grupo estaba formado por los indígenas, colonos de estos propietarios y cuya población oscilaba entre 500 y 600 habitantes.

Mientras existió este sistema Taquile estaba estratificada en dos grupos, de los cuales el de los indígenas constituía una verdadera clase social en la isla, pertenecía al nivel inferior dentro de la estratificación social del país, respondía a patrones culturales tradicionales, se mantenía en un proceso mínimo de mestizaje y había una serie de factores locales que correspondían a una situación general de toda la región rural andina serrana del país, propia del mundo de las comunidades indígenas (más de 4000 con una población de mas de tres millones de habitantes o comuneros). El otro grupo, por su pequeñez y su sola orientación a la explotación económica, no constituía clase social en Taquile, aún cuando como mestizos en Puno sí pertenecían a una clase social nacional, pero en la isla su influencia no tenía el peso necesario, ni el número, ni la conciencia de clase por su fugaz presencia.

Los indígenas constituían el gran grupo de colonos de los hacendados y como tal la estructura económica y social respondía a este tipo de relaciones. Ubicada en el contexto nacional, la isla Taquile era una de las tantas haciendas del país donde unas pocas familias dominaban a un grupo de 600 habitantes, a los que tenían sujetos a toda clase de servicios y trabajos, con lo cual estas familias de clase media puneña o representativa del grupo de mayores ingresos se aferraba a ser propietarias de tierras aun cuando sea en una islita del lago, para así tener el estatus de hacendados y gozar de los servicios personales de los indígenas en sus lugares de origen.

Al iniciar los indígenas la lucha por la propiedad y al ir pasando de la situación de colonos a la de propietarios, han roto una valla que para muchos grupos indígenas es todavía infranqueable, salvo el caso de que intervengan diversos agentes como en Vicos (Callejón de Huaylas) en que se ha expropiado la hacienda. En Taquile, por el contrario, por acción de sus mismos pobladores se está produciendo el paso de hacienda a comunidad. He aquí el hecho social trascendental para la isla. Dentro del proceso que actualmente vive, como lo hemos expuesto ampliamente es de esperar que en los próximos años desaparezca definitivamente toda propiedad foránea y que el grupo quede completamente liberado de propietarios mestizos. El actual remanente de estos mistis no tiene ya mayor significación y desde ahora podemos constatar como está gestándose la nueva estructura económica y social en la isla.

Aunque los taquileños admiten que entre ellos pueden distinguirse tres grupos: los acomodados, integrados actualmente por 24 familias; los intermedios, constituidos por 49 familias; y los pobres que agrupan a 40 familias, nosotros hemos considerado cuatro, porque creemos que está más de acuerdo con la realidad.

En el primer grupo, que podemos llamar de los más acomodados, destacan cuatro familias, los Huata, los Flores, los Mamani y los Cruz, debido a una serie de factores. En primer lugar por constituir familias numerosas, o sea responder al patrón tradicional de familia extensa. Así, los Huata comprenden a tres familias nucleares que viven juntas; los Flores están integrados por cuatro familias nucleares; los Mamani y los Cruz por dos familias cada una. En segundo lugar, por sus condiciones personales, en ellas se encuentran los grandes líderes de la isla, a ellos se debe la actual transformación, sobresaliendo en forma especial la familia Huata. Otros factores serían poseer las mayores extensiones de 
tierra cultivable y el mayor número de animales domésticos; ser los principales accionistas de los botes de vela; contar entre sus componentes a personas que hablan castellano; $y$, por último, que están familiarizados con diversos mecanismos nacionales, debido a las luchas por la posesión de la tierra y por sus viajes a Lima y alrededores de Puno.

Pero en este pequeño grupo de las cuatro familias más acomodadas sobresale en forma nítida la familia Huata, que es virtualmente la más importante y la que tiene la mejor posición económica y social de la isla, lo que en buena parte también se debe a la recia personalidad de dos de sus miembros, Prudencio y Lino Huata.

Antes de llegar a ser propietarios, este grupo ya ocupaba un estatus de prestigio entre los isleños. Las aspiraciones de sus pobladores estaban cifradas en ellos que eran sus adalides y su ganado prestigio lo tenían por sus condiciones personales, por el tremendo esfuerzo desplegado en el aprovechamiento intensivo de la tierra, por la herencia familiar que en un momento dado les permitió juntar, por constituir familias extensas, más tierras y disponer de más brazos para trabajarlas. Todo esto hizo posible que reunieran dinero para iniciar las primeras gestiones de compra de tierras. Este grupo era considerado por estos atributos como los capac, o sea los ricos, pero sin que en su posición lo económico significara la discriminación fundamental. Este grupo, al ser propietario y disponer de tierras en cantidad superior a las que sus necesidades les demandaban, afirmaba así su poder económico y su definitivo liderazgo en la isla.

La posesión de mayores propiedades y la riqueza en dinero ha comenzado a jugar en Taquile un papel de primera importancia para señalar la posición que una persona o una familia tenga en la comunidad. Las nuevas autoridades nacionales surgen del grupo de los más acomodados y cuando la comunidad se enfrenta a la vida nacional es por intermedio de ellos que lo hace y se les reconoce tal actitud como un deber. Además, por el hecho de poseer tantas tierras y recoger buenas cosechas que les permite un gran excedente para la venta, son mirados, por el resto con envidia y sorpresa, porque muchos, los más pobres, ven en ellos a los nuevos gamonales y los acusan de no haber repartido equitativamente a todas las familias las tierras que ellos, los ricos, con su dinero adquirieron de los "mistis" y esto porque la mentalidad del poblador común sigue todavía pensando en término de igualdad, mientras que el nuevo grupo emergente piensa como el mestizo, y ha adquirido los valores predominantemente individualistas que caracterizan a la cultura mestiza. Pero este indígena rico no está todavía suficientemente aculturado como para no reflexionar sobre esta situación y aún cuando entre 1937 y 1954 pensaba en términos puramente mercantilistas, "como pueden quejarse, decía Prudencio Huata, si todo se debe a mi esfuerzo, muchas veces me abandonaron y acusaron en los momentos más difíciles y ahora reclaman".

Actualmente parece que la actitud va cambiando y a pesar de que ellos también tienen colonos, en estos últimos años están tratando de vender parte de sus propiedades a aquellos que pueden adquirirlas. Pero aún así no llegará a producirse una equitativa distribución de tierras en la comunidad. Estas familias y algunas otras que se incorporen a este grupo dispondrán dentro de poco de capital y experiencia y estimulados por la difusión cultural lograrán las conquistas de que actualmente gozan los grupos mestizos en el altiplano y otras regiones andinas. Y esto ya comienza a aparecer.

Los Huata tienen actualmente a uno de sus hijos estudiando en una escuela de Lima, han adquirido una serie de elementos de la técnica moderna que los sitúa en una posición privilegiada: un fonógrafo, una carretilla, batería de cocina de aluminio, reloj, linternas, etc., y piensan adquirir una radio y un motor fuera de borda para su embarcación. Todavía no se ha alterado en ninguno de los componentes de este grupo las características de su equipo tradicional, visten y comen como los demás, ni olvidan ninguna de las creencias 
y prácticas mágico-religiosas. Solamente lo que les diferencia de los demás es el mayor número de elementos tradicionales básicos, más ropa corriente y de fiestas, más instrumentos de labranza, más viviendas y chozas, más vacunos, etc. Pero, parece que, por lo dicho anteriormente, ahora que han colmado sus viejas aspiraciones, cancelado sus deudas y logrado adquirir propiedades, las próximas ganancias que obtengan los llevará a asumir una rápida transformación y veremos en ellos a los representantes del nuevo grupo mestizo emergente de Taquile.

Las 20 familias restantes, del conjunto que los taquileños consideran acomodadas, para nuestra apreciación constituyen el segundo grupo o nivel dentro de la actual estratificación social de la comunidad. Muchas de ellas integrarán en el futuro el pequeño grupo de los más acomodados, debido a sus relaciones familiares, pues los matrimonios entre los miembros de este grupo y el de los más acomodados comienzan a producirse y hemos constatado que en sus elecciones ambos grupos buscan que así sea, aunque no en forma excluyente.

El tercer grupo estaría integrado por los cacnioc, los que tienen suficiente para vivir según expresión de ellos. Unas 49 familias. Es interesante comprobar que tanto del grupo de los acomodados como de estos canioc surgen las autoridades tradicionales: los mandones. A pesar de que ya existen autoridades políticas nacionales: el Teniente Gobernador, un Agente Municipal, un Sargento jefe de Playa, las autoridades tradicionales constituyen todavía el elemento fundamental en el gobierno local de la comunidad. Ellos conservan todo el prestigio, respeto y atribuciones que nunca han perdido desde el siglo XVI, siempre a pesar de ser colonos tuvieron "mandones", mantuvieron la clásica división de los seis suyo y de los dos ayllu o mitades en que se divide la isla y aún cuando ésta pertenecía a los mestizos, los mandones velaban por el cumplimiento del sistema agrario tradicional, cuidaban y vigilaban las chacras y juzgaban todos los conflictos entre los indígenas. Esta situación conocida por los dueños de fuera, fue respetada y nunca reprimida. Además, los que llegaban a ser mandones eran los escogidos por los patrones para ser kipus (mayordomos). Aunque tradicionales, existe toda una jerarquía y rigidez, que ni el prestigio de los líderes actuales, ni la nueva situación han alterado, sino que por el contrario han robustecido.

Para ser autoridad comunal, es necesario tener una familia regular. Uno de los principales líderes de la isla, de condiciones excepcionales, nunca ha llegado a ser mandón, debido a que tiene un hogar inestable y él nunca lo ha solicitado, no obstante disponer de la fuerza para hacerlo. Los cargos se desempeñan, rigurosamente desde los 18 años, como ayudante para que se vayan entrenando en las funciones importantes y solamente cuando son casados pueden ejercer los cargos de Hilacata o de Alcalde. Las autoridades son elegidas cada año en votación pública, mediante ternas que proponen las autoridades salientes, de acuerdo con toda la comunidad. Esta ceremonia del camachicoc indígena supervive con todo vigor. Nadie puede ser Alcalde, sino ha sido antes Hilacata. Y cuando se llega al cargo superior, Alcalde Mayor es porque realmente se tiene condiciones. Todos los Alcaldes Mayores al cesar en sus cargos pueden ser elegidos Segundo, especie de asesores y el conjunto de Segundos cesantes forma el Consejo de Ancianos. Lo formal en todo jefe de familia de cierta edad es haber sido Segundo, los que no lo han alcanzado, tienen un estatus inferior y cuando en el censo preguntamos los cargos desempeñados pudimos comprobar claramente que el grupo mediante estas elecciones había clasificado a sus miembros en niveles de prestigio bien claros. Los flojos o los que cometieron alguna irregularidad se quedan solamente como Campo Alcalde o Alcalde Menor. Los incapaces apenas llegan a ser Hilacatas. El ser autoridad depende pues de la capacidad e inteligencia del isleño y como tal es un factor que determina su posición social en el grupo. 
El cuarto grupo integrado por 40 familias constituye el nivel de los pobres, determinado principalmente por no tener productos suficientes para su propia alimentación anual y por ello tener que dedicarse a actividades complementarias que son consideradas por la comunidad en forma un tanto peyorativa, como la pesca en las orillas y el trabajo de la piedra.

Estos niveles que hemos señalado no pueden ser considerados definitivos, debido a la gran movilidad social motivada por el contacto con el exterior, ahora más intenso que nunca, y a las posibilidades que el trabajo les ofrece en centros como Arequipa, Tacna y Lima, todo lo cual contribuye a cambios notables. Los matrimonios, aunque son orientados en forma preponderante entre los dos primeros niveles, ocurren muchas veces debido a la capacidad de trabajo de los pobres. Por sus condiciones personales, simpatía o habilidades, las mujeres de los dos primeros niveles pueden casarse con los considerados pobres sin ser rechazados por sus respectivos grupos. Por otra parte, hemos constatado como los pobres que han servido en el ejército y que están aprendiendo castellano o los niños que van en mayor número a la escuela salen a trabajar fuera de la isla y pasando penurias logran reunir dos o tres mil soles en uno o dos años, para después regresar a la isla a comprar tierras y trabajarlas activamente. Todos tienen actualmente la oportunidad de adquirir tierras de los remanentes que quedan en poder de los dueños de fuera; así como de los más acomodados que venden parte de sus propiedades.

Taquile está en plena transición y como tal todas sus actividades están sufriendo un impacto, cuyas consecuencias se traducirán en la transformación de una comunidad tradicional a ser una comunidad mestiza, con valores que ellos imitarán de sus propios vecinos. ${ }^{4}$

Lo lamentable en todo esto es que al no existir organismos nacionales o factores en juego que señalen pautas a este proceso que es general a muchas regiones del país, la nueva comunidad entrará a un sistema que creemos no sea el más favorable a sus valores tradicionales, ni a la sociedad nacional ${ }^{5}$.

\section{Comentarios a esta publicación}

\section{0 años después de haberlo escrito}

El presente articulo es un capitulo de la tesis doctoral del suscrito sustentada el primero de julio de 1958 para optar el grado de Doctor en Letras, Especialidad Etnología, en la Facultad de Letras de la Universidad Nacional Mayor de San Marcos.

El título de la tesis es LA ESTRUCTURA ECONÓMICA DE UNA COMUNIDAD ANDINA Taquile. - Una isla del Lago Titicaca. La cual consta de tres partes. La primera incluye una introducción, el estudio etnológico, el área cultural de la Meseta del Collao y la isla Taquile y la estructura económica y el cambio cultural. La segunda la Estructura Económica de una comunidad andina dividida en cuatro partes: economía; actividades productivas (pesca, crianza y utilización de animales, agricultura, alimentación y bebidas, tejidos, vestido y vivienda); trabajo; viaje y transporte. La tercera parte La Propiedad.

4 Hoy, 50 años después de haber escrito este articulo, Taquile es una comunidad de éxito, de punta, como las he denominado y como muchas otras en el país. Comunidad emergente desarrollada por el impacto del turismo, la belleza de la isla por su ubicación y la extraordinaria habilidad textil y musical de sus habitantes.

5 Versión revisada el 24 de junio de 2008. 


\section{Antecedentes}

Esta tesis forma parte de un estudio más amplio sobre Taquile, el cual está en plena preparación como un libro sobre lo que era la isla en 1952, organizado en tres partes y cuyo titulo será: TAQUILE. Suyu (economía), mandón (política) y Mulusina (lo mágicoreligioso).

El estudio etnológico en Taquile fue realizado entre 1950 y 1952 por el suscrito y su esposa, antropóloga, la señora Rosalía Ávalos Alva.

Formó parte del proyecto inicial de estudios etnológicos del Gabinete de Trabajo del Instituto de Etnología de la Facultad de Letras de la Universidad Nacional Mayor de San Marcos, cuyo director era el doctor Luis E. Valcárcel y el jefe de Gabinete el suscrito.

El proyecto gestado y llevado a cabo desde 1947, un año después de la fundación de la especialidad de etnología en la Universidad, iniciaba los trabajos de campo de los primeros etnólogos peruanos, entonces hoy antropólogos, tendiente, según las orientaciones dominantes en la década de 1940, a conocer el mundo indígena peruano de entonces, agrupado especialmente en sus más de cuatro a cinco mil comunidades de indígenas. Su propósito fundamental era contribuir a tratar de conocer las posibles supervivencias existentes en cientos de comunidades y grupos indígenas del mundo rural peruano sobre lo que fue la alta cultura o civilización Inca antes de 1532. La idea de relicto o supervivencia planteada por el doctor Valcárcel y en otro campo por el doctor Julio C. Tello inspiraron, motivaron e hicieron posible los estudios pioneros de Tupe, Taquile y Huarochiri. Revalorando al mismo tiempo lo que significaba el mundo indígena, discriminado, deprimido y pobre en el seno de la sociedad nacional peruana.

Específicamente Taquile es el segundo estudio de esta naturaleza. El primero fue Tupe, en Yauyos entre 1947 y 1950, y el tercero Huarochiri en 1952-55.

El trabajo de campo en la isla Taquile fue realizado en 1950, 1951 y 1952 y formó parte de un proyecto más amplio y ambicioso, conocer la vida de los pescadores ubicados en las orillas del lago Titicaca y en especial la actual situación del grupo marginal, que como relicto de los primeros habitantes que llegaron a América del Sur, aún subsistían en la zona, conocidos como los Urus, viviendo parte en Puno y cuyo núcleo principal estaba en Iru-Itu, Ankoaque, río Desaguadero, a corta distancia del lago. El proyecto fue organizado por el doctor Jehan Vellard, Director del Instituto Francés de Estudios Andinos y profesor del curso de Etnología Sudamericana del Instituto de Etnología y Arqueología de la Universidad Nacional Mayor de San Marcos.

El doctor Vellard anteriormente los había estudiado en 1937 y buscaba conocer su evolución y precisar las zonas de expansión de sus patrones culturales dentro del conjunto de los grupos de pescadores del lago.

Con el fin de completar este plan de estudio de los famosos uru, el doctor Vellard nos encomendó el estudio de las islas del lago. Después de recorrerlas constatamos que la más interesante por su aislamiento y sus características era Taquile. Para el suscrito el plan encajaba con el proyecto inicial del Instituto de Etnología. Conocer una comunidad quechua aislada en una región tan importante como el lago Titicaca, zona de confluencia de los idiomas quechua y aimara. Así estudiaríamos un relicto diferente al de la sierra del departamento entonces de Lima y abriríamos un nuevo frente que, complementado con los trabajos importantes que se realizaban en el valle de Urubamba y el Cusco en general, en el valle de Mantaro y en el callejón de Huaylas, nos permitirían ofrecer una visión nueva de la realidad indígena peruana, como parte sustantiva de diagnosticar el Perú de entonces. 


\section{Las ediciones del artículo "La Propiedad en la isla Taquile"}

Esta es la cuarta edición de este estudio sobre la propiedad en Taquile. La primera en francés, versión resumida, en 1953, en la revista Travaux de L'Institut Francais d'Etudes Andines, tomo III, volumen unique, París, Lima, 1951. La segunda en la Revista del Museo Nacional, (Museo de la Cultura Peruana) Tomo XXVI, pp. 211-271. Lima. 1957. La tercera en la serie de publicaciones del Instituto de Etnología y Arqueología, Facultad de Letras, Universidad Nacional Mayor de San Marcos, Publicación N. ${ }^{\circ}$ 13, 1958 (separata de la Revista del Museo Nacional). La cuarta en el libro Estudios sobre la cultura actual del Perú, editado con prólogo de José María Arguedas por la Universidad Nacional Mayor de San Marcos, Lima, 1964, pp. 64-142.

El libro Estudios sobre la cultura actual del Perú, publicado en 1964 reúne una serie de artículos que seleccionamos con apoyo del asistente del Gabinete de Trabajo del Instituto de Etnología el antropólogo Alberto Cheng Hurtado y que fueron después de ser revisados aceptados por el doctor Luis E. Valcárcel. Su intención fue ofrecer una muestra de los mejores estudios antropológicos existentes y que abarcaban una gama de temas, conocimientos y puntos de vista de los pioneros estudios realizados: Mangin sobre el mundo urbano popular limeño y el Callejón de Huaylas, Farón sobre los orígenes del sistema de hacienda en la costa, Matos Mar la comunidad indígena en el lago Titicaca, Mishkin las comunidades indígenas del este del Cusco, Gabriel Escobar las comunidades de indígenas del valle de Mantaro, Arguedas Puquio pueblo indígena en Ayacucho y Núñez del Prado la comunidad de los Quero en Paucartambo, Cusco.

Al ausentarme por dos años a Venezuela, esta recopilación preparada en 1958 quedó pendiente dentro de la serie de publicaciones del Departamento de Antropología. José María Arguedas que quedó a cargo del Gabinete de Trabajo con la colaboración de Alberto Cheng Hurtado hicieron posible que estos trabajos fuesen publicados por la Universidad.

Finalmente adelantamos la noticia. Desde la década de 1980, Taquile es una comunidad de punta, o sea de éxito, al haber incorporado el turismo como uno de sus actividades fundamentales, en más de 28 años, hoy 2008 Taquile tiene renombre nacional y reconocimiento universal. Sus tejidos, sus bailes de tropas de sikuris, la belleza de su isla, su recreación y modernización son un ejemplo de la potencialidad de la comunidad campesina en el Perú moderno. Como Taquile existen por lo menos más de 50 comunidades extraordinariamente exitosas demostrando que el ayllu andino milenario hasta 1532, convertido en reducciones de indios, pequeños centros poblados de la república de indios surgidos por la conquista y coloniaje español con fines de adoctrinamiento, extirpación de idolatrías, mano de obra y control ante el temor de una rebelión indígena, reconocidas como comunidades de indígenas al surgir la República en 1821 hasta la reforma agraria de 1969 y después como comunidades campesinas, constituye la supervivencia de una creación autóctona que agrupa la mayor población que vive en el mundo a alturas mayores de $3500 \mathrm{~m}$ de altitud y que espera que el Perú oficial las recree, potencie y modernice, porque ninguna otra organización social, cultural y económica está mejor adaptada a un espacio tan agreste y de extraordinaria potencialidad de recursos. 